\title{
Approaches Towards Fighting COVID-19 in Taiwan
}

\author{
Shih-Chang Tsai ${ }^{1}$, Chi-Cheng $\mathrm{Lu}^{2}$, Da-Tian Bau ${ }^{3}$, Yu-Jen Chiu ${ }^{4}$, Yu-Ting Yen ${ }^{1}$, Yuan-Man \\ $\mathrm{Hsu}^{1}$, Chih-Wei Fu ${ }^{5}$, Sheng-Chu Kuo ${ }^{1}$, Yu-Shiang Lo ${ }^{3}$, Hong-Yi Chiu ${ }^{6}$, Yu-Ning Juan ${ }^{3}$, \\ Fuu-Jen Tsai ${ }^{1}$, and Jai-Sing Yang ${ }^{3}$ \\ ${ }^{1}$ China Medical University \\ ${ }^{2}$ National Taiwan University of Sport \\ ${ }^{3}$ China Medical University Hospital \\ ${ }^{4}$ Taipei Veterans General Hospital \\ ${ }^{5}$ Industrial Technology Research Institute \\ ${ }^{6}$ Buddhist Tzu Chi General Hospital
}

May 21, 2020

\begin{abstract}
The coronavirus disease 2019 (COVID-19) outbreak, which has caused millions of confirmed infections and thousands of deaths, has been the most devastating worldwide crises recently. The main clinical symptoms of confirmed COVID-19 cases include fever, dry cough, general fatigue, respiratory symptoms, diarrhoea and sore throat, similar to those of acute respiratory distress syndrome. SARS-CoV-2, the causative agent of COVID-19, belongs to a novel coronavirus strain against which no drug or vaccine currently exists. Therefore, research units around the world have been actively developing efficient diagnostic tools and new drugs. This review summarises the clinical manifestations of COVID-19, analyses the viral genome sequence and life cycle, identifies methods for preventing viral transmission, discusses possible molecular pharmacologic mechanisms and approaches in the development of anti-SARS-CoV-2 virus therapeutic agents and introduces management measures against COVID-19 in Taiwan, especially policies for a name-based mask distribution system. Finally, we summarise traditional Chinese medicines (TCM) for COVID-19. Based on all the information accumulated in this review, development of novel anti-viral agents, vaccines for SARS-CoV-2 therapy or an effective combination therapy can be expected. Finally, we would like to extend our best regards to the frontline health workers in their global fight against COVID-19.
\end{abstract}

Key words: COVID-19; SARS-CoV-2; clinical manifestations; preventing viral transmission; molecular pharmacologic mechanisms; Taiwan

\section{Abbreviations}

ACE2, Angiotensin-converting enzyme 2; ARDS, Acute respiratory distress syndrome; CQ, Chloroquine; CT, Computed tomography; COVID-19, Coronavirus disease 2019; 3CLpro, 3-chymotrypsin-like cysteine protease; cDNA, Complementary DNA; DPP4, Dipeptidyl peptidase 4; FDA, Food and Drug Administration; ExoN, Helicase and exonuclease; HCQ, Hydroxychloroquine; MERS-CoV, Middle East respiratory syndrome coronavirus; NGS, Next generation sequencing platforms; NSPs, Non-structural proteins; ORFs, Open reading frames; PICALM, Phosphatidylinositol binding clathrin assembly protein; RdRp, RNA-dependent RNA polymerase; rRT-PCR, Real-time reverse transcriptase polymerase chain reaction; SARS-CoV-2, Severe Acute Respiratory Syndrome Coronavirus 2; SARS-CoV, Severe Acute Respiratory Syndrome Coronavirus; TCDC, Taiwan Centers for Disease Control; TCM, Traditional Chinese medicines; TFDA, Taiwan Food and Drug Administration; TMPRSS2, Transmembrane protease serine 2.

\section{INTRODUCTION}


The coronavirus disease 2019 (COVID-19) outbreak has spread worldwide with an overwhelming speed, infecting at least 4,921,252 individuals and causing 322,039 deaths across almost 200 countries as of 20 May 2020 (Wu, Chen \& Chan, 2020). COVID-19, caused by SARS-CoV-2 virus, hit China, the US and European countries considerably hard, with the aforementioned countries becoming the epicentres of the SARS-CoV-2 virus pandemic (Liu, Kuo \& Shih, 2020). Based on previous experience with SARS, the Taiwanese government had decided to block viral transmission during its early stages. Presently, early blockage of SARS-CoV-2 transmission has been the key point in protecting against COVID-19 (Liu, Kuo \& Shih, 2020; Tsay, Kao, Wang \& Lin, 2020). Confirmed cases in Taiwan have been lower than those in other countries. Accordingly, the Taiwan Centers for Disease Control (TCDC) (Wu, Chen \& Chan, 2020) had reported 440 confirmed cases and seven deaths on 20 May 2020(Figure 1A). Majority of the confirmed cases were indigenous and imported, with a peak age of 20-29 years (Figure 1B) .

Strategies aimed at interrupting interactions between the virus and host have been primarily utilised from the viewpoint of public epidemiology (Chang \& McAleer, 2020; Hsu et al., 2020). To contain the spread of the virus, several countries have closed accesses to international flights, locked down the entire country or several cities and instructed the public to follow social distancing measures. Moreover, body temperatures are being measured wherever people congregate and social activities have been diminished in hopes of curbing peak prevalence and death (Hsu et al., 2020; Schwartz, King \& Yen, 2020; Wu, Chen \& Chan, 2020). No therapeutic agents and vaccines have currently been approved by the US Food and Drug Administration (FDA) (2020a) and Taiwan Food and Drug Administration (TFDA) for SARS-CoV-2 virus infections (2020d). As such, the development of novel agents and vaccines against SARS-CoV-2 has been the most researched subject worldwide.

Taiwan, which is only 81 miles away from the coast of China, with whom Taiwan shares intensive commercial intercourse, has been constantly alert and ready to act on potential epidemics arising from China considering the insufferable experiences gained from the severe acute respiratory syndrome epidemic of 2003. Given that most patients shared nonspecific clinical and laboratory findings, comprehensive surveillance of detailed exposure history for suspected patients and application of rapid detection tools are required. Through the combination of border control, rapid testing and quarantine of individuals with contact history, isolation, real-time linking of informative records with the healthcare system and protection of health care worker safety through Traffic Control Bundling, Taiwan had been able to effectively control the COVID-19 epidemic (Wang, Ng \& Brook, 2020; Yen, Schwartz, Chen, King, Yang \& Hsueh, 2020).

The current review summarises the clinical manifestations, cases, SARS-CoV-2 viral genome structure and sequence, SARS-CoV-2 viral life cycle, diagnosis, preventive methods and management measures of COVID19, as well as the name-based mask distribution system in Taiwan. Finally, we provide an overview of the possible molecular pharmacologic mechanisms of anti-SARS-CoV-2 agents and the synthesis of remdesivir (GS-5734), chloroquine (CQ) and hydroxychloroquine (HCQ), as well as summarise traditional Chinese medicines (TCM) for COVID-19.

\section{CLINICAL CHARACTERISTICS OF COVID-19}

According to current literatures, fever, dry cough and fatigue have been the most common symptoms at the onset of COVID-19, with other symptoms including muscle pain, productive cough, headache, diarrhoea, dyspnoea and haemoptysis (Figure 2) (Park, 2020). Symptoms generally appear approximately 5.2 days after COVID-19 (Li et al., 2020a). Although up to 50\%-75\% of patients with COVID-19 remain asymptomatic, approximately $14 \%$ present with serious symptoms requiring hospitalisation and oxygen therapy, while $5 \%$ require intensive care. The median duration from symptom onset to intensive care unit admission was around 10 days, while the duration between symptom onset and death ranged from approximately 2 to 8 weeks (Chang, Wu \& Chang, 2020; Day, 2020; Li et al., 2020a; Zhou et al., 2020a).

Laboratory findings include elevated lactate dehydrogenase and ferritin levels. Moreover, although white blood cell counts can vary, leucopoenia and lymphopenia have been most commonly observed findings. Chest radiography and computed tomography (CT) findings are diverse and nonspecific, commonly presenting as 
multiple ground-glass opacity lesions, bilateral patchy shadowing or local patchy shadowing. Severe cases tend to yield more prominent radiologic findings (Wang et al., 2020a). However, a few cases have presented with no imaging abnormality (17.9\% of non-severe cases and $2.9 \%$ of severe cases) (Park, 2020). As the disease progresses, multiple ground-glass opacity lesions may progress into consolidation or superimposed interlobular/intralobular septal thickening (i.e., crazy-paving pattern), which may expand consolidation (Tu et al., 2020). Several similarities exist between COVID-19 symptoms and those caused by other atypical pathogens. However, COVID-19 exhibits some distinctive clinical characteristics, including targeting of the lower respiratory tract instead of the upper respiratory tract, which produces symptoms like sneezing, rhinorrhoea and sore throat (Assiri et al., 2013). Moreover, chest radiographs and CT scans upon patient admission revealed an infiltrate in the upper lobe of the lung that was associated with increasing dyspnoea with hypoxemia (Phan et al., 2020). Some patients with COVID-19 also developed gastrointestinal distress, such as diarrhoea, whereas only a low percentage of patients with Middle East respiratory syndrome coronavirus (MERS-CoV) or severe acute respiratory syndrome coronavirus (SARS-CoV) experienced the same (Rothan \& Byrareddy, 2020). Lastly, most of the patients with COVID-19 exhibited leucopoenia and lymphopenia on admission. Tan et al. demonstrated that patients with blood lymphocyte percentage (LYM\%) $>20 \%$ are in the process of recovery. In contrast, those with $5 \%<\mathrm{LYM} \%<20 \%$ are still in danger, while those with LYM\% $<5 \%$ become critically ill with high mortality rate and require intensive care (Tan et al., 2020). Lymphopenia seems to be an effective and reliable indicator of severity and hospitalisation among patients with COVID-19 (Su \& Lai, 2020).

Table 1 presents a classification of the clinical manifestations of COVID-19 in Taiwan (Wang, Ng \& Brook, 2020). A few case reports in Taiwan have been published online in Table 2 . The first 11 patients with COVID-19 in Taiwan (3 males and 8 females) received treatment in a single-occupant negative-pressure room. The median duration of symptom onset following COVID-19 confirmation was $4.2 \pm 2.9$ days. Common symptoms included cough (60\%), fever (50\%), flu-like symptoms (40\%), rhinorrhoea (30\%), and infiltrations on chest radiography (30\%). Other less common symptoms included muscle ache (10\%), sore throat (10\%) and shortness of breath (10\%) (Cheng et al., 2020a; Cheng et al., 2020b; Huang et al., 2020b; Lee et al., 2020; Liu, Liao, Chang, Chou \& Lin, 2020; Su \& Lai, 2020).

\section{STRUCTURE, GENOME SIZE AND LIFE CYCLE OF SARS-CoV-2}

Coronaviruses mainly cause respiratory and gastrointestinal tract infections and are genetically classified into four major genera: Alpha-coronavirus, Beta-coronavirus, Gamma-coronavirus and Delta-coronavirus (Wu et al., 2020a). Six types of human coronaviruses have been previously identified, which include HCoV-NL63 and $\mathrm{HCoV}-229 \mathrm{E}$ belonging to the Alpha-coronavirus genus and $\mathrm{HCoV}-\mathrm{OC} 43, \mathrm{HCoV}-\mathrm{HKU}$, SARS-CoV and MERS-CoV belonging to the Beta-coronavirus genus (Wu et al., 2020a). Coronaviruses had not attracted worldwide attention until the 2003 SARS pandemic, followed by the 2012 MERS and, most recently, COVID19 outbreaks (Wu et al., 2020a). Both SARS-CoV-2 and MERS-CoV have been considered highly pathogenic (Singhal, 2020). Figure 3shows the schematic structure of SARS-CoV-2 (Lee et al., 2020; Rabaan et al., 2020).

SARS-CoV-2 has a genome length of approximately 30 kilobasepairs (kb). Accordingly, SARS-CoV-2 genome sequences from NCBI (Li \& De Clercq, 2020; Yen, Schwartz, Chen, King, Yang \& Hsueh, 2020), covering between approximately 798 and 29,674 bases, include a variable number of open reading frames (ORFs) (Figure 4 ). The first ORF, representing approximately $67 \%$ of the entire genome, encodes two large polyproteins, PP1a and PP1ab, which are proteolytically cleaved into 16 non-structural proteins (NSPs), including papain-like protease, 3-chymotrypsin-like cysteine protease (3CLpro), RNA-dependent RNA polymerase (RdRp), helicase and exonuclease (ExoN). The remaining ORFs encode accessory and structural proteins. The four major structural proteins include the spike surface glycoprotein (S), envelope protein (E), matrix protein (M) and nucleocapsid protein (N) (Adachi, Koma, Doi, Nomaguchi \& Adachi, 2020; Boopathi, Poma \& Kolandaivel, 2020; Cui, Li \& Shi, 2019; Li \& De Clercq, 2020). Recent studies have revealed six major non-structural protein subtypes (nsp3, nsp4, nsp6, nsp12, nsp13 and nsp14) for SARSCoV-2 (Junior, Polveiro, Souza, Bortolin, Sassaki \& Lima, 2020). Spike proteins of viruses bind to host 
cell receptors for entry. Accordingly, the spike proteins of SARS-CoV-2 and MERS-CoV bind to different host receptors through different receptor-binding domains. SARS-CoV-2 uses angiotensin-converting enzyme 2 (ACE2) as one of the main receptors with CD209L as an alternative receptor, whereas MERS-CoV uses dipeptidyl peptidase 4 (DPP4, also known as CD26) as its primary receptor (Boopathi, Poma \& Kolandaivel, 2020; Chan et al., 2006; Chen, Strych, Hotez \& Bottazzi, 2020; Jeffers et al., 2004; Li \& De Clercq, 2020; Verdecchia, Cavallini, Spanevello \& Angeli, 2020). The cleavage of trimer S protein is initiated by the cell surface-associated transmembrane protease serine 2 (TMPRSS2) and cathepsin (McKee, Sternberg, Stange, Laufer \& Naujokat, 2020; Stahlmann \& Lode, 2020).

The life cycle of SARS-CoV-2 can be categorised into nine major steps (Figure 5 ). Upon binding to ACE2 and TMPRSS2, SARS-CoV-2 enters host target cells through either fusion or endocytosis (step 1). In the endocytic pathway, the SARS-CoV-2 envelope fuses with the endosome membrane in the lysosomal acid environment, which promotes viral RNA genome release into the host cell cytoplasm (step 2). ORF1a/b encoding 3CLpro is then translated for the replication of genomic RNA (step 3). Thereafter, replicase polypeptide is cleaved (proteolysis), producing NSPs, such as RNA-dependent RNA polymerase (RdRp) and helicase (step 4). SARS-CoV-2 then undergoes viral RNA replication in the host cells (step 5). The viral sub-genome is transcribed (step 6). Viral nucleocapsid (N), membrane (M), envelope (E) and spike (S) are translated through the endoplasmic reticulum and Golgi apparatus (step 7). N protein and other structural proteins interact with viral genomic RNA to pack and form a novel virion (step 8). The assembled virion is then released via exocytosis into the extracellular compartment (step 9). The released viral particle is infectious and may begin a new life cycle (Figure 5 ) (Kupferschmidt \& Cohen, 2020; Li et al., 2020a).

\section{DIAGNOSTIC METHODS FOR COVID-19 IN TAIWAN}

Two approaches have generally been utilised for the diagnostic screening of SARS-CoV-2: (1) real-time reverse transcriptase polymerase chain reaction (rRT-PCR) and (2) rapid screening (Yan et al., 2020; Yip et al., 2020). Detection time and duration until COVID-19 diagnosis are detailed in Table 3 .

\subsection{REAL-TIME REVERSE TRANSCRIPTASE POLYMERASE CHAIN REACTION TESTING}

The rRT-PCR assay utilises viral RNA extracted from patient samples (e.g., material collected through nasopharyngeal and oropharyngeal swabs), synthesises complementary DNA (cDNA) through the action of the reverse transcriptase enzyme, and amplifies target sequences of the viral genome from the cDNA template. RT-PCR can be interpreted semi-quantitatively, with the target amplification speed dependent on the concentration and quality of the viral RNA in the initial sample, thereby allowing the amplification rate to be used as a proxy for the sample viral load (Yan et al., 2020). The three target screening assays include E (envelope) gene assay, RdRp gene assay and N (nucleocapsid) gene assay (Figure 6) (Rahman et al., 2020). For a routine workflow, the TCDC recommends the E gene assay as the first-line screening tool, followed by confirmatory testing with the RdRp gene assay. Utilising the RdRp gene assay with dual colour technology can discriminate between SARS-CoV-2 (both probes positive) and SARS-CoV RNA provided that the latter is used as a positive control. Alternatively, laboratories may choose to run the RdRp assay with only the SARS-CoV-2-specific probe. Despite also performing well, the $\mathrm{N}$ gene assay had not been subjected to further intensive validation given its slightly inferior sensitivity (Lee et al., 2020; Pujadas et al., 2020).

\subsection{RAPID SCREENING}

Five antibody-based tests have been used for detecting the presence of $\operatorname{IgG}$ and $\operatorname{IgM}$ in body fluids, such as whole blood, serum or plasma. The BioMedomics rapid test and Surescreen rapid test cassette utilise lateral flow immunoassays, which are diagnostic devices used to examine antibodies (Li et al., 2020a; Montesinos et al., 2020; Thabet et al., 2020; Vasarhelyi, Kristof, Ostorhazi, Szabo, Prohaszka \& Merkely, 2020). Moreover, Goldsite diagnostics had designed a time-resolved fluorescence immunoassay kit, while the Assay Genie rapid POC kit and VivaDiag COVID-19 IgG-IgM test are colloidal gold-based immunoassays for detecting viral infection (Yan et al., 2020). To conduct the assay, a few drops of blood obtained from the general public 
using a finger-stick or vein are applied onto the immunoassay. A few drops of buffer solution are then added onto the assay, after which the results will be within 10-15 min at room temperature. RT-PCR testing is used as the reference standard to which immunoassays compared. Among the five rapid screening tests, the BioMedomics IgM-IgG rapid test has been widely used for detecting antibody production in the human body (Huang et al., 2020a).Table 4 summaries the current diagnostic methods for COVID-19 in Taiwan.

\section{POSSIBLE METHODS FOR PREVENTING COVID-19 IN TAIWAN}

SARS-CoV-2 possesses several properties, such as transmission from asymptomatic individuals and nonspecific features of COVID-19, and utilises the ACE2 and TMPRSS2 receptors for attachment and transmission (Lange et al., 2020; Pujadas et al., 2020). Both ACE2 and TMPRSS2 proteins are expressed in less than $10 \%$ of human respiratory and gastrointestinal tract cells, including nasal goblet secretory cells, lung type II pneumocytes, ileal absorptive enterocytes (Wong, Lui \& Sung, 2020; Zhou et al., 2020b; Ziegler et al., 2020). At present, prevention of viral entry into the human body has been the best option for controlling viral spread. The TCDC has established technical guidelines for COVID-19 available at website (Day, 2020). The following are crucial steps for preventing viral spread:

1. Stay at home: the general public should avoid travelling to affected countries and regions, as well as contact with animals dead or alive. The general public should make a habit of applying alcohol-based hand sanitisers after entering the rooms.

2. Maintain decontamination: Rooms should undergo regular decontamination preferably with $5 \%$ to $10 \%$ Sodium hypochlorite.

3. Keep a safe social distance: the general public must avoid public gatherings. Individuals should

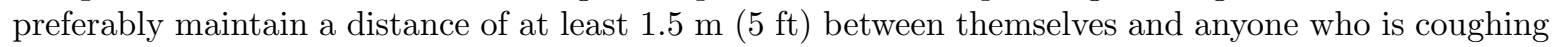
or sneezing indoors. Individuals may maintain a distance of at least $1 \mathrm{~m}(3 \mathrm{ft})$ distance between themselves and anyone outdoors.

4. Maintain clean hands: Individuals are advised to practice proper hygiene, such as frequent handwashing with soap after sneezing or coughing. Avoid touching any secretions, such as stool or urine. In addition, individuals should refrain from touching their eyes, nose and mouth with unclean hands.

5. Wear face masks: Healthcare personnel must use personal protective equipment, such as medical masks (including surgical face masks and N95s), eye protection, gloves, gowns and protective gear. The general public must wear a face mask to help prevent viral transmission. Given the supply shortages, each country has their own recommendations regarding wearing of face masks.

The Taiwanese government has developed guidelines to protect the health and safety of the public from the global novel coronavirus outbreak.Figure $\mathbf{7}$ details the processing of the name-based mask distribution system in Taiwan (Lai, Wang, Wang, Hsueh, Ko \& Hsueh, 2020). While medical and surgical masks should be prioritised for health care workers, the general public can wear cloth face masks made from household items, such as two layers of cotton fabric, T-shirts or bedsheets.

Medical masks can reduce the transmission of respiratory droplets to others and prevent blood or other potentially infectious materials from reaching the wearer's skin, mouth or mucous membranes. Masks function by filtering $5-\mu \mathrm{m}$ particles from the air reaching the mouth/nose.Figure $\mathbf{8}$ and Table $\mathbf{5}$ summarise the medical mask materials and associated principles (Bartoszko, Farooqi, Alhazzani \& Loeb, 2020; Hirschmann, Hart, Henckel, Sadoghi, Seil \& Mouton, 2020; Long et al., 2020; Ma, Shan, Zhang, Li, Yang \& Chen, 2020; Saadat, Rawtani \& Hussain, 2020). In addition, the structure and composition of the different virus families occur affect their reaction to disinfectants. Components, such as 75\% Ethanol (Brewer \& Streel, 2020; Henwood, 2020; Zhao, Liu, Liu, Li \& Zhang, 2020; Ziegler et al., 2020), Sodium hypochlorite (1000 ppm (0.1\%) 10,000 ppm (1\%)) (Henwood, 2020; Kampf, Todt, Pfaender \& Steinmann, 2020; Ma, Shan, Zhang, Li, Yang \& Chen, 2020), Hypochlorous acid (10 ppm 30 ppm) (Chen, Zhang, Wang, Zhu \& Liu, 2006; Henwood, 2020; Kampf, Todt, Pfaender \& Steinmann, 2020; Ma, Shan, Zhang, Li, Yang \& Chen, 2020), Chlorine dioxide (Chen, Zhang, Wang, Zhu \& Liu, 2006), Soap (Jones, Walsh, Willcox, Morgan \& Nichols, 2020; Ma, Shan, Zhang, Li, Yang \& Chen, 2020) and Hydrogen peroxide (0.5\%) (Caruso, Del Prete, Lazzarino, Capaldi \& Grumetto, 2020; Cheng, Wong, Kwan, Hui \& Yuen, 2020; Torres et al., 2020) and others (Schrank, 
Minbiole \& Wuest, 2020; Verbeek et al., 2020) have been used to kill bacteria and viruses. Table 5 lists the chemical formula and preparation concentration of the disinfectants, as well as associated principles.

\section{CURRENT THERAPEUTIC MODALITIES FOR COVID-19 IN TAIWAN}

Given the lack of clinical evidence supporting the efficacy of any existing anti-viral agent or vaccine against COVID-19, supportive treatments for clinical conditions in the early stages is imperative. Taiwanese guidelines propose the immediately provision of supplemental oxygen therapy to patients with respiratory distress, hypoxemia or shock. In addition, conservative fluid management should be employed among patients with COVID-19 when no evidence of shock is present. Details and targets of supportive treatments for clinical conditions in Taiwan are presented in Table 6 (Wang, Ng \& Brook, 2020).

Several ongoing clinical trials have evaluated the following direct treatments for SARS-CoV-2: chloroquine (Aralanß), hydroxychloroquine (Plaquenil@), arbidol (Umifenovir@), camostat mesylate (Foipan $\AA$ ), remdesivir (GS-5734), favipiravir (Aviganß), ribavirin (Rebetol@), lopinavir/ritonavir (Kaletraß) and interferon- $\alpha$, interferon- $\beta$ (Kupferschmidt \& Cohen, 2020). The chemical structures of hydroxychloroquine (Plaquenil@), chloroquine (Aralan $\AA$ ), remdesivir (GS-5734), favipiravir (Avigan $\AA$ ), ribavirin (Rebetol@), lopinavir/ritonavir (Kaletra $\Omega$ ), and camostat mesylate (Foipan $囚$ ) are presented in Figure $\mathbf{9}$. Accordingly, the Taiwanese guidelines indicate that early 7-day treatment with hydroxychloroquine (Plaquenilß) may be considered after doctors' evaluation and informed consent. Table 7 details the dosages of hydroxychloroquine (Plaquenil@) and special considerations, including adverse effects (retinopathy and QT prolongation) (Wang, Ng \& Brook, 2020). Currently, three clinical trials on COVID-19 are ongoing in Taiwan (NCT 04292899, NCT 04292730 and NCT 03808922), with remdesivir as the primary anti-COVID-19 agent being focused in Table $\mathbf{8}$ ( Tu et al., 2020). Table $\mathbf{9}$ andFigure 10 subsequently summarise ongoing therapeutic agents against COVID-19 and their molecular pharmacologic mechanisms.

Suitable therapeutic agents against SARS-CoV2 carry the following actions:

(1) Block coronavirus-host interactions and attachments: Camostat mesylate (Foipanß) (Huang, Song, Huang \& Sun, 2020; Rahman, Basharat, Yousuf, Castaldo, Rastrelli \& Khan, 2020) and arbidol (Umifeno$\operatorname{vir}($ ) ) (Vankadari, 2020; Zhu et al., 2020).

(2) Trigger lysosomal activation and disrupting intracellular trafficking: Hydroxychloroquine (Plaquenil@) and chloroquine (Aralanß) (Li et al., 2020a; Pastick et al., 2020; Piszczatoski \& Powell, 2020; Shukla, Archibald, Shukla, Mehta \& Cherabuddi, 2020) .

(3) Inhibit RNA-dependent RNA polymerase: Remdesivir (GS-5734), favipiravir (Aviganß) (Ahsan, Javed, Bratty, Alhazmi \& Najmi, 2020; Amawi, Abu Deiab, AA, Dua \& Tambuwala, 2020; Du \& Chen, 2020; McKee, Sternberg, Stange, Laufer \& Naujokat, 2020; Wu et al., 2020b).

(4) Interfere with RNA metabolism required for viral replication: Ribavirin (Rebetol@) (Chan, Wong \& Tang, 2020; Jean, Lee \& Hsueh, 2020; Martinez, 2020).

(5) Inhibit 3CLpro: Lopinavir/Ritonavir (Kaletra@); (Ahsan, Javed, Bratty, Alhazmi \& Najmi, 2020; Martinez, 2020; Simsek Yavuz \& Unal, 2020).

(6) Functioning as immunotherapeutic agents: Type 1 interferon, IFN- $\alpha$, pegylated interferon $\alpha-2 a$ and $\alpha-2 b$ and interferon- $\beta$ (Ahsan, Javed, Bratty, Alhazmi \& Najmi, 2020; Chan, Wong \& Tang, 2020; Martinez, 2020; Sallard, Lescure, Yazdanpanah, Mentre \& Peiffer-Smadja, 2020).

\subsection{BLOCKING CORONAVIRUS-HOST INTERACTIONS AND ATTACHMENTS: CAMO- STAT MESYLATE (FOIPAN@) AND ARBIDOL (UMIFENOVIR@)}

Camostat mesylate (Foipan $\AA$ ) is a serine protease inhibitor that inhibits TMPRSS2 and blocks virus entry into lung cells (Rahman, Basharat, Yousuf, Castaldo, Rastrelli \& Khan, 2020). In vitro studies have shown that camostat mesylate (Foipan (R) inhibits TMPRSS2 and blocks SARS-CoV and human coronavirus NL63 infection of HeLa cells (Huang, Song, Huang \& Sun, 2020; Rahman, Basharat, Yousuf, Castaldo, Rastrelli 
\& Khan, 2020). Hoffmann et al. demonstrated that SARS-CoV-2 exploits ACE-2 for entry and serine protease TMPRSS2 for S protein priming (Hoffmann, Kleine-Weber \& Pohlmann, 2020; Hoffmann et al., 2020; Hoffmann, Schroeder, Kleine-Weber, Muller, Drosten \& Pohlmann, 2020). Moreover, reports have shown that camostat mesylate (Foipan@) blocks SARS-CoV-2 infection of Calu-3 lung cells in vitro (Huang, Song, Huang \& Sun, 2020). Accordingly, four clinical trials on camostat mesylate for COVID-19 are currently ongoing worldwide (NCT 04353284, NCT 04321096, NCT 04338906 and NCT 04355052) (Tu et al., 2020).

Arbidol (Umifenovir $(\mathrm{B})$ is a small indole-derivative agent used for the treatment of respiratory viral infections (Amawi, Abu Deiab, AA, Dua \& Tambuwala, 2020; Deng et al., 2020; Vankadari, 2020; Zhu et al., 2020).In vitro and in vivo studies have demonstrated that arbidol inhibits a number of enveloped or non-enveloped RNA or DNA viruses, including influenza viruses A, B, C, SARS-CoV, adenovirus, poliovirus, rhinovirus, coxsackievirus, Hantaan virus, Chikungunya virus and Hepatitis B and C viruses (Deng et al., 2020; Dong, Hu \& Gao, 2020; Wang et al., 2020b). Arbidol (Umifenovirß) interacts with aromatic residues within the viral hemagglutinin glycoprotein and inhibits viral entry (Hulseberg et al., 2019; Kadam \& Wilson, 2017; Zeng, Yang \& Liu, 2017). A total of eight clinical trials on arbidol for COVID-19 have been ongoing worldwide (NCT 04350684, NCT 04286503, NCT 04260594, NCT 04323345, NCT 04273763, NCT 04306497, NCT 04261907 and NCT 04333589) (Tu et al., 2020).

\subsection{TRIGGERING LYSOSOMAL ACTIVATION AND DISRUPTING INTRACELLU- LAR TRAFFICKING: CHLOROQUINE (ARALAN@) AND HYDROXYCHLOROQUINE (PLAQUENIL@)}

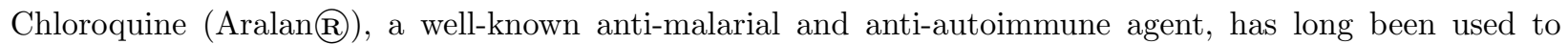
treat malaria and autoimmune diseases, such as systemic lupus erythematosus and rheumatoid arthritis. Hydroxychloroquine (Plaquenil@) is synthesised by introducing a hydroxyl group into chloroquine. Animal studies had demonstrated that hydroxychloroquine (Plaquenil@) was much less toxic than chloroquine (Li et al., 2020a; Pastick et al., 2020; Piszczatoski \& Powell, 2020; Shukla, Archibald, Shukla, Mehta \& Cherabuddi, 2020).

Reports have shown that chloroquine and hydroxychloroquine increase endosomal and lysosomal pH (alkalinises vacuolar $\mathrm{pH}$ ) and then disrupt intracellular trafficking (Annangi, 2020; Badyal \& Mahajan, 2020; Colson, Rolain, Lagier, Brouqui \& Raoult, 2020; Ferner \& Aronson, 2020; Sturrock \& Chevassut, 2020). Recent studies have demonstrated that chloroquine reduces the expression of phosphatidylinositol binding clathrin assembly protein (PICALM), a cargo-selecting clathrin adaptor that senses and drives membrane curvature, which regulates endocytosis (Dong, Hu \& Gao, 2020). In vitro studies have demonstrated that chloroquine significantly inhibits SARS-CoV-2 from infecting Vero E6 cells. One of the mechanisms for the chloroquine-mediated effects against SARS-CoV-2 is the decrease in the ability of cells to perform clathrin-mediated endocytosis of nanosized structures due to PICALM suppression (Dong, Hu \& Gao, 2020).

Clinical investigations have shown that patients with COVID-19 had high concentrations of cytokines, such as IL-1 $\beta$, IL-1 $\beta$, IL-2, IL-6, IFNs and MCP-1 (Lagunas-Rangel \& Chavez-Valencia, 2020; McGonagle, Sharif, O'Regan \& Bridgewood, 2020; Ren et al., 2020), in their plasma, subsequently causing a cytokine storm. In addition, hydroxychloroquine has been demonstrated to exhibit anti-inflammatory activity and can significantly decrease the IL-1, IL-6, TNF $\alpha$ and TNF production through Toll-like receptor (TLR)/NF- $x$ B signalling (Aizawa, Imaizumi, Hirono, Watanabe, Tsugawa \& Tanaka, 2019; Clancy, Markham, Reed, Blumenberg, Halushka \& Buyon, 2016).

The molecular pharmacologic mechanisms of chloroquine and hydroxychloroquine are summarised in Figure 11. A total of 52 clinical trials on chloroquine and 150 clinical trials on hydroxychloroquine for the treatment of COVID-19 have been ongoing (Tu et al., 2020). Given that chloroquine and hydroxychloroquine are longstanding therapeutic agents widely used for disease treatment in hospitals, several ongoing clinical trials on COVID-19 have focused on both.

6.3 INHIBITING RNA-DEPENDENT RNA POLYMERASE: REMDESIVIR (GS-5734) AND FAVIPIRAVIR (AVIGAN@) 
Remdesivir (GS-5734), a phosphoramidate prodrug of an adenine-derivative agent, was originally developed by Gilead Sciences (Gilead Sciences Inc., Foster City, CA, USA) (patent holder) for the Ebola virus (Augustin, Hallek \& Nitschmann, 2020; Cao, Deng \& Dai, 2020; Li, Wang, Cao, Sun, Li \& Li, 2020; Reina, 2020). Meanwhile, favipiravir (Avigan $\AA$ ), a guanine-derivative agent, has been approved for influenza A infection among patients resistant to Tamiflu and Relenza treatment in Taiwan (Jean, Lee \& Hsueh, 2020; Li et al., 2020a; Lu, Chen \& Chang, 2020). Remdesivir and favipiravir are incorporated into nascent viral RNA and inhibit the RNA-dependent RNA polymerase (RdRp) (Jean, Lee \& Hsueh, 2020; Lu, Chen \& Chang, 2020). This results in the premature termination of the viral RNA chain and consequently halts the replication of the viral genome. Recent in vitro studies have reported that remdesivir and favipiravir possess bioactivities against SARS-CoV-2 (Choy et al., 2020; Jean, Lee \& Hsueh, 2020; Simsek Yavuz \& Unal, 2020). Our preliminary studies using Discovery Studio 2020 (DS 2020) software revealed that remdesivir and favipiravir had a strong binding ability to RNA-dependent RNA polymerase (RdRp) (Figure 12 and Supplementary Table 1). A total of 19 clinical trials on remdesivir and 12 clinical trials on favipiravir for the treatment of COVID-19 are ongoing (Tu et al., 2020). On April, 29, 2020, a National Institutes of Health clinical trial reported remdesivir accelerates recovery from COVID-19. On May, 1, 2020, the US FDA issued an emergency authorisation for the use of investigational remdesivir in the treatment of suspected or laboratory-confirmed COVID-19 among adults and children hospitalised with severe disease (Zhou et al., 2020a). This is positive and exciting news for the treatment of COVID-19.

\subsection{INTERFERING WITH RNA METABOLISM REQUIRED FOR VIRAL REPLICATION: RIBAVIRIN (REBETOL@)}

Ribavirin, a guanosine-derivative agent, had been approved for the treatment of Hepatitis C virus infection. Recent studies have demonstrated that ribavirin can be used to treat respiratory syncytial virus and SARSCoV by inhibiting viral RNA synthesis, viral mRNA capping and RNA-dependent RNA polymerase (Elfiky, 2020a; Elfiky, 2020b; Guzik et al., 2020; Jean, Lee \& Hsueh, 2020). Five clinical trials on ribavirin for the treatment of COVID-19 have been ongoing worldwide (Tu et al., 2020).

\subsection{INHIBITING 3-CHYMOTRYPSIN-LIKE CYSTEINE PROTEASE (3CLPRO): LOPINA- VIR/RITONAVIR (KALETRA@)}

Lopinavir and ritonavir have been widely used for treating HIV infection. However, early studies have demonstrated that lopinavir and ritonavir are active against SARS-CoV and MERS by inhibiting 3CLpro via proteolysis in SARS-CoV (Costanzo, De Giglio \& Roviello, 2020; Deng et al., 2020; Ye et al., 2020). However, Cheng et al. demonstrated that Kaletra $($ did not shorten the duration of SARS-CoV-2 infection among patients with mild pneumonia in Taiwan (Cheng et al., 2020a). Our preliminary studies using Discovery Studio 2020 (DS 2020) software showed that lopinavir and ritonavir had strong binding ability to 3CLpro(Figure 13 and Supplementary Table 1). A total of 45 clinical trials on Kaletra@ for the treatment of COVID-19 have been ongoing worldwide (Tu et al., 2020).

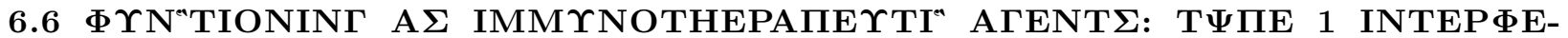

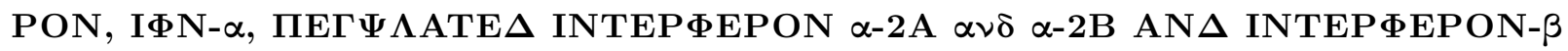

During viral infection, type I interferon synthesis is initially induced, which subsequently activates both innate and adaptive immune response against the virus. The type I interferon family consists IFN- $\alpha$, IFN- $\beta$ and other subtypes (Andreakos \& Tsiodras, 2020; Du et al., 2020; Sallard, Lescure, Yazdanpanah, Mentre \& Peiffer-Smadja, 2020). When the virus infects target cells, RNA sensors induces interferon regulatory transcription factor translocation into the nucleus, which promotes type I interferon secretion. The secreted interferon interacts with interferon receptors on the cell membrane, which promotes phosphorylation of STAT1/2 transcriptional factors (Nelemans \& Kikkert, 2019; Vidal, 2020). The phosphorylation of STAT1/2 re-localises to the nucleus, binds to interferon-stimulated response element responsible for activating interferon-stimulated genes, which then produces more type I interferon. Upon type I interferon secretion, type I interferon-mediated innate immunity is triggered. Natural killer cells then become active and destroy infected cells. Type I interferon binds to the interferon receptors on cytotoxic T cells $\left(\mathrm{CD} 8^{+} \mathrm{T}\right.$ 
cells), subsequently killing infected cells through cellular immunity (Langevin, Aleksejeva, Passoni, Palha, Levraud \& Boudinot, 2013). In addition, type I interferon stimulates B cells and induces neutralising antibody production, which plays a protective role by limiting later-phase infections and preventing future re-infections (Nelemans \& Kikkert, 2019). Treatment with IFN- $\alpha 2$ b significantly reduced the duration of SARS-CoV-2 in the upper respiratory tract and reduced inflammatory cytokine IL-6 and CRP in COVID-19 patients (Zhou et al., 2020c).

Cells infected with SARS-CoV and MERS-CoV exhibited reduced type I interferon. As such, it can be speculated that SARS-CoV-2 utilises a similar manner for type I interferon reduction. Previous studies have reported that type I interferon treatments improved anti-SARS-CoV and anti-MERS-CoV activity among infected mice and had synergistic effects with ribavirin against SARS-CoV in vitro (Morgenstern, Michaelis, Baer, Doerr \& Cinatl, 2005). Immunocompromised patients are at higher risk for severe COVID-19 than the general public. Type I interferon treatments can thus be a safe and efficient approached against SARSCoV-2 infection (Mantlo, Bukreyeva, Maruyama, Paessler \& Huang, 2020; Sallard, Lescure, Yazdanpanah, Mentre \& Peiffer-Smadja, 2020). A total of 37 clinical trials on interferon for COVID-19 have been ongoing worldwide (Tu et al., 2020). Figure 14 presents a schematic overview of the type I interferon-mediated immune response mechanism following SARS-CoV, MERS-CoV and SARS-CoV-2 infection.

\section{SYNTHESIS OF REMDESIVIR, CHLOROQUINE AND HYDROXYCHLOROQUINE}

Remdesivir (Compound 12) was synthesised by Siegel et al. as illustrated in Scheme 1 (Figure 15) (Siegel et al., 2017). The iodo-based compound 1 was reacted with Turbo Grignard reagents via metal-halogen exchange, followed by the addition of ribolactone $\mathbf{2}$ to afford the glycosylation product $\mathbf{3}$. Treatment of $\mathbf{3}$ with TMSCN, TMSOTf and TfOH at -78 afforded $\mathbf{4}$, which yielded benzyl deprotection product5 after reacting with $\mathrm{BCl}_{3}$. Acetonide protection of the 2',3'-hydroxyl moieties with 2,2-dimethoxypropane in the presence of $\mathrm{H}_{2} \mathrm{SO}_{4}$ afforded 6 . 2-Ethyl-1-butanol $\mathbf{7}$ and L-alanine 8 were treated with $\mathrm{HCl}_{(\mathrm{g})}$ to generate ester product 9 , which was reacted with $\mathrm{OP}(\mathrm{OPh}) \mathrm{Cl}_{2}$ under base conditions, followed by 4-nitrophenol to obtain the $p$-nitrophenolate 2-ethylbutyl-L-alaninate prodrug precursor $\mathbf{1 0}$. The coupling reaction between 6 and 10under $\mathrm{MgCl}_{2}$ generated 11, after which in situ acetonide deprotection was performed through concentrated $\mathrm{HCl}$ to afford target molecule remdesivir (Compound 12) .

As shown in Figure 16, chloroquine (Compound 25) was synthesised by Drake N. L. et al. and Price Ch. C. et al. as described in Scheme 2 (Drake, Creech \& et al., 1946; Price \& Roberts, 1946). Accordingly, 4,7-Dichloroquinoline $\mathbf{1 9}$ was prepared from 3-chloroaniline $\mathbf{1 3}$ via 1,4-addition with ethoxymethylenmalonic acid $\mathbf{1 4}$, thermal heterocyclisation, hydrolysis, decarboxylation and $\mathrm{POCl}_{3}$ chlorination. Novaldiamine $\mathbf{2 4}$ was synthesised following three steps. Acetoacetic ester $\mathbf{2 0}$ alkylation with 2-diethylaminoethylchloride $\mathbf{2 1}$ generated 2-diethylaminoethylacetoacetic acid ester $\mathbf{2 2}$, which yielded 1-diethylamino-4-pentanone $\mathbf{2 3}$ upon acidic hydrolysis using hydrochloric acid and simultaneous decarboxylation. Reductive amination of this compound with hydrogen and ammonia using Raney nickel as a catalyst yielded $\mathbf{2 4}$. Nucleophilic aromatic substitution of chlorine at C-4 in $\mathbf{1 9}$ with novaldiamine $\mathbf{2 4}$ generated the desired molecule chloroquine $\mathbf{2 5}$.

Finally, we provide two methods (pathways) for the synthesis of hydroxychloroquine by Synthia Organic Retrosynthesis Software (Merck, Taiwan) in the Supplementary document.

\section{TRADITIONAL CHINESE MEDICINES (TCM) TCM AND COVID-19}

The clinical practice of TCM in Taiwan has been extraordinarily limited given the few confirmed cases and well-established protocols of modern Western medication for patients with COVID-19 in Taiwan (Wang, $\mathrm{Ng} \&$ Brook, 2020). Thus, we surveyed the literature regarding the design, efficacy and safety of TCM alone or in conjunction with medical therapies mostly published in China and highlight several of them (in the following sections or in Table 10 ) (Luo et al., 2020a; Luo et al., 2020b; Ma et al., 2020; Ni, Zhou, Zhou, Zhao \& Wang, 2020; Qing, Zhang, Bai \& Luo, 2020; Ren, Zhang \& Wang, 2020; Rosa \& Santos, 2020; Ul Qamar, Alqahtani, Alamri \& Chen, 2020; Wan et al., 2020; Wang et al., 2020c; Zhang, Zhang, Lv, Sa, Zhang \& Lin, 2020). Based on more than 3500 years of Chinese medical practice, TCM has spread to many countries worldwide, has profoundly influenced people's lives and has gradually assimilated with 
modern Western medicine and therapy. In recent decades, mounting evidence has suggested that TCM can be helpful in the prevention and treatment of human virus-related disorders, including influenza, liver diseases and acquired immune deficiency syndrome (Chan, Wong \& Tang, 2020; McKimm-Breschkin, Jiang, Hui, Beigel, Govorkova \& Lee, 2018; Teschke, Larrey, Melchart \& Danan, 2016; Zhang, Cong, Zhang, Guo $\& \mathrm{Li}, 2020)$. For instance, Jinxin oral liquid, modified from Ma Xing Shi Gan Decoction, has been proven to be therapeutically effective and safe in the treatment of viral pneumonia both in clinical and experimental studies (Lin et al., 2016). However, the detailed intracellular mechanisms remain largely unknown. The central dogma for pneumonia TCM therapy includes excreting phlegm, reducing fever, relieving cough and dyspnoea and resolving all disorders (Gray \& Belessis, 2020; Ho, Chan, Chung \& Leung, 2020; Lin et al., 2016; Zhang, Zhang, Lv, Sa, Zhang \& Lin, 2020).

After the COVID-19 outbreak, TCM scheme had been included into the guidelines for the diagnosis and therapy of COVID-19 in China (Chan, Wong \& Tang, 2020; Ho, Chan, Chung \& Leung, 2020; Hu, Logue \& Robinson, 2020). Among all the TCMs examined in clinical practice, the Qing Fei Pai Du Decoction has been reported to be most effective and safety for COVID-19 (Ren, Zhang \& Wang, 2020). Specifically, Shuang Huang Lian oral liquid treatment helped patients recover from the infection with few apparent side effects (Ni, Zhou, Zhou, Zhao \& Wang, 2020). Ma Xing Shi Gan Decoction, for instance, has been shown to reduce inflammation responses and suppress the cytokine storm, thereby protecting the pulmonary alveolar-capillary barrier, alleviating pulmonary enema and reducing body temperature (Wang et al., 2020c). Lastly, using the prediction system based on molecular interaction simulation and docking score calculation, Ul Qamar and colleagues have proposed that 9 out of 32,297 anti-viral TCMs in the database have the highest affinity with the viral 3-chymotrypsin-like cysteine protease enzyme, which is critical for the proliferation and life cycle of COVID-19 (Ul Qamar, Alqahtani, Alamri \& Chen, 2020). Generally, TCMs capable of reducing fever, relieving cough through improved immunity have been candidates for patients suffering from COVID-19. These may include glycyrrhiza, ephedra, bitter almond, gypsum, reed root, amomum and trichosanthes (Luo et al., 2020b). The researches in China has patterned several TCMs, including Reduning injection, Suhuang Zhike capsule and Xue Bi Jing, for the treatment of COVID-19 (Wang, Chen, Lu, Chen \& Zhang, 2020).

As shown in Table 10, healthy individuals can also take TCMs to prevent COVID-19 by strengthening whole-body immunity (Chan, Wong \& Tang, 2020; McKimm-Breschkin, Jiang, Hui, Beigel, Govorkova \& Lee, 2018; Teschke, Larrey, Melchart \& Danan, 2016; Zhang, Cong, Zhang, Guo \& Li, 2020). Chinese doctors have also recommended Buzhong Yiqi Decoction, Yu Ping Feng San, Yin Qiao San and Sang Chu Yin for adjusting endogenous Qi and preventing infection. Moreover, Yin Qiao San may be effective in reducing selfor clinically confirmed fever, with or without a sore throat, and reversing the damage to the respiratory tracts, while Sang Chu Yin is capable of relieving cough and reducing sputum production. The two aforementioned groups belong to the mild stage. According to the TCM theory, the target organ of COVID-19 is the lungs, while the aetiology can be attributed to a 'damp and toxin plague'. The network pharmacology analysis showed that Qing Fei Pai Du Decoction has an overall multi-component and multi-target regulatory effect. In addition, it exerted protective effects for the heart, kidney and other organs. Other TCMs, such as Jin Hua Qing Gan Granule, Lian Hua Qing Wen Capsule, Xue Bi Jing Injection, Hua Shi Bai Du Formula and Xuan Fei Bai Du Granule, have also been used for the treatment of clinically severe/critical disease, during which personalised medication and care is of extreme importance (Luo et al., 2020a; Luo et al., 2020b; Ma et al., 2020; Ni, Zhou, Zhou, Zhao \& Wang, 2020; Qing, Zhang, Bai \& Luo, 2020; Ren, Zhang \& Wang, 2020; Rosa \& Santos, 2020; Ul Qamar, Alqahtani, Alamri \& Chen, 2020; Wan et al., 2020; Wang et al., 2020c; Zhang, Zhang, Lv, Sa, Zhang \& Lin, 2020).

We believe that more convenient methods for the early detection of COVID-19 via genotyping will emerge in the near future. Within a short span of time, suspected individuals could also be detected and identified through several biomarkers, such as those related to their anti-inflammation, anti-oxidant, anti-viral and anti-mutational capacities. After genotyping procedures, each subject could be prescribed appropriate and personalised TCM treatments among those listed in Figure $\mathbf{1 7}$ for the effective prevention of COVID-19 or its progression into severe or critical disease. Overall, TCMs can help reduce the typical COVID-19 progression to mid/moderate and severe/critical disease. Even among severe/critical cases, TCMs can still 
serve as a complementary and integrative therapy to modern Western medicine to shorten the recovery period and relieve symptoms among patients with COVID-19.

\section{CONCLUDING REMARKS}

This review describes several clinical manifestations of COVID-19, analyses the SARS-CoV-2 genome and outlines the life cycle of SARS-CoV-2. Several methods have been used to examine SARS-CoV-2 infections. For example, RT-PCR has been applied for RNA detection, while rapid screening has been used for antibody or virus detection. The Taiwanese government has established several policies for controlling viral spread. Despite the lack of medications for COVID-19, many clinical trials have been proposed for its treatment. In addition, several TCMs have been discussed for the readers' reference.

To avoid direct contact with suspected COVID-19 cases, viral secretions and infected droplets, the following relevant preventive measures should be followed:

(1) Pay attention to and cooperate with the latest epidemic prevention policies issued by the government.

(2) Maintain hand hygiene habits, particularly avoiding touching the eyes, nose and mouth with unclean hands.

(3) Maintain social distancing or wear masks, avoid crowded public places and taking public transportation.

(4) Reduce hospital visits except for urgent medical needs.

(5) Comply with relevant regulations if home quarantined or in isolation.

(6) Stop working or going to school when sick.

(7) Inform your medical providers about your travel history, contact history, occupation and cluster history.

We expect Taiwan to globally interact and cooperate with other countries to develop rapid and accurate screening assays, produce vaccines, design novel agents against SARS-CoV-2 and reduce the side effects of therapeutic TCMs. Ultimately, our long-term goal is to be free from COVID-19.

\section{ACKNOWLEDGEMENTS}

This work was supported by the project from Dr. Jai-Sing Yang of China Medical University Hospital (grant no. DMR-109-147), and in part by the project from Dr. Shih-Chang Tsai of China Medical University (grant no. CMU-103-S-16). We thank Kuan-Wen Chen and Tzu-Mao Hung in GGA Corporation, Molecular Science Center (Taiwan) for performing the molecular docking to RDRP and 3C-like protease (3CLpro). We wish to acknowledge the work of Nian-Gu Chen, Pei-Jen Chung, Chien-Jung Huang, Yi-Chia Li and Chia-Wen Tsai for their assistance on this work. We also thank Merck Ltd. Taiwan company for providing Synthia Organic Retrosynthesis Software.

\section{CONFLICT OF INTEREST}

The authors declare that they have no competing interests.

\section{References}

(2020a). Food and Drug Administration (FDA). https://www.fda.gov/.

(2020b). https://clinicaltrials.gov/.

(2020c). Interim Guidelines for Clinical Management of SARS-CoV-2 Infection (5th edition). https://www.cdc.gov.tw/File/Get/-ewtg9-RCAetCPKR4_rnCw.

(2020d). Taiwan Food and Drug Administration (TFDA). https://www.fda.gov.tw/ENG/index.aspx.

Adachi S, Koma T, Doi N, Nomaguchi M, \& Adachi A (2020). Commentary: Origin and evolution of pathogenic coronaviruses. Front Immunol 11: 811. 
Adachi T, Chong JM, Nakajima N, Sano M, Yamazaki J, Miyamoto I, et al. (2020). Clinicopathologic and Immunohistochemical Findings from Autopsy of Patient with COVID-19, Japan. Emerg Infect Dis 26.

Ahsan W, Javed S, Bratty MA, Alhazmi HA, \& Najmi A (2020). Treatment of SARS-CoV-2: How far have we reached? Drug Discov Ther 14:67-72.

Aizawa T, Imaizumi T, Hirono K, Watanabe S, Tsugawa K, \& Tanaka H (2019). Chloroquine attenuates TLR3-mediated plasminogen activator inhibitor-1 expression in cultured human glomerular endothelial cells. Clin Exp Nephrol 23: 448-454.

Amawi H, Abu Deiab GI, AA AA, Dua K, \& Tambuwala MM (2020). COVID-19 pandemic: an overview of epidemiology, pathogenesis, diagnostics and potential vaccines and therapeutics. Ther Deliv.

Andreakos E, \& Tsiodras S (2020). COVID-19: lambda interferon against viral load and hyperinflammation. EMBO Mol Med.

Annangi S (2020). Chloroquine and hydroxychloroquine for COVID-19: A word of caution. Respirology.

Assiri A, Al-Tawfiq JA, Al-Rabeeah AA, Al-Rabiah FA, Al-Hajjar S, Al-Barrak A, et al. (2013). Epidemiological, demographic, and clinical characteristics of 47 cases of Middle East respiratory syndrome coronavirus disease from Saudi Arabia: a descriptive study. Lancet Infect Dis 13: 752-761.

Augustin M, Hallek M, \& Nitschmann S (2020). [Remdesivir for patients with severe COVID-19]. Internist (Berl).

Badyal DK, \& Mahajan R (2020). Chloroquine: Can it be a Novel Drug for COVID-19. Int J Appl Basic Med Res 10: 128-130.

Baron DM, Franchini M, Goobie SM, Javidroozi M, Klein AA, Lasocki S, et al. (2020). Patient blood management during the COVID-19 pandemic: a narrative review. Anaesthesia.

Bartoszko JJ, Farooqi MAM, Alhazzani W, \& Loeb M (2020). Medical masks vs N95 respirators for preventing COVID-19 in healthcare workers: A systematic review and meta-analysis of randomized trials. Influenza Other Respir Viruses.

Boopathi S, Poma AB, \& Kolandaivel P (2020). Novel 2019 coronavirus structure, mechanism of action, antiviral drug promises and rule out against its treatment. J Biomol Struct Dyn: 1-10.

Brewer C, \& Streel E (2020). Is Alcohol in Hand Sanitizers Absorbed Through the Skin or Lungs? Implications for Disulfiram Treatment. Alcohol Alcohol.

Cao YC, Deng QX, \& Dai SX (2020). Remdesivir for severe acute respiratory syndrome coronavirus 2 causing COVID-19: An evaluation of the evidence. Travel Med Infect Dis: 101647.

Caruso AA, Del Prete A, Lazzarino AI, Capaldi R, \& Grumetto L (2020). May hydrogen peroxide reduce the hospitalization rate and complications of SARS-CoV-2 infection? Infect Control Hosp Epidemiol: 1-5.

Chan KW, Wong VT, \& Tang SCW (2020). COVID-19: An Update on the Epidemiological, Clinical, Preventive and Therapeutic Evidence and Guidelines of Integrative Chinese-Western Medicine for the Management of 2019 Novel Coronavirus Disease. Am J Chin Med 48: 737-762.

Chan VS, Chan KY, Chen Y, Poon LL, Cheung AN, Zheng B, et al.(2006). Homozygous L-SIGN (CLEC4M) plays a protective role in SARS coronavirus infection. Nat Genet 38: 38-46.

Chang CL, \& McAleer M (2020). Alternative Global Health Security Indexes for Risk Analysis of COVID-19. Int J Environ Res Public Health 17.

Chang TH, Wu JL, \& Chang LY (2020). Clinical characteristics and diagnostic challenges of pediatric COVID-19: A systematic review and meta-analysis. J Formos Med Assoc 119: 982-989. 
Chen C, Zhang XJ, Wang Y, Zhu LX, \& Liu J (2006). Waste water disinfection during SARS epidemic for microbiological and toxicological control. Biomed Environ Sci 19: 173-178.

Chen WH, Strych U, Hotez PJ, \& Bottazzi ME (2020). The SARS-CoV-2 Vaccine Pipeline: an Overview. Curr Trop Med Rep: 1-4.

Cheng CY, Lee YL, Chen CP, Lin YC, Liu CE, Liao CH, et al.(2020a). Lopinavir/ritonavir did not shorten the duration of SARS CoV-2 shedding in patients with mild pneumonia in Taiwan. J Microbiol Immunol Infect.

Cheng SC, Chang YC, Fan Chiang YL, Chien YC, Cheng M, Yang CH, et al. (2020b). First case of Coronavirus Disease 2019 (COVID-19) pneumonia in Taiwan. J Formos Med Assoc 119: 747-751.

Cheng VCC, Wong SC, Kwan GSW, Hui WT, \& Yuen KY (2020). Disinfection of N95 respirators by ionized hydrogen peroxide during pandemic coronavirus disease 2019 (COVID-19) due to SARS-CoV-2. J Hosp Infect.

Choy KT, Wong AY, Kaewpreedee P, Sia SF, Chen D, Hui KPY, et al.(2020). Remdesivir, lopinavir, emetine, and homoharringtonine inhibit SARS-CoV-2 replication in vitro. Antiviral Res 178: 104786.

Clancy RM, Markham AJ, Reed JH, Blumenberg M, Halushka MK, \& Buyon JP (2016). Targeting downstream transcription factors and epigenetic modifications following Toll-like receptor $7 / 8$ ligation to forestall tissue injury in anti-Ro60 associated heart block. J Autoimmun 67: 36-45.

Cleemput S, Dumon W, Fonseca V, Karim WA, Giovanetti M, Alcantara LC, et al. (2020). Genome Detective Coronavirus Typing Tool for rapid identification and characterization of novel coronavirus genomes. Bioinformatics.

Colson P, Rolain JM, Lagier JC, Brouqui P, \& Raoult D (2020). Chloroquine and hydroxychloroquine as available weapons to fight COVID-19. Int J Antimicrob Agents 55: 105932.

Corman VM, Landt O, Kaiser M, Molenkamp R, Meijer A, Chu DK, et al. (2020). Detection of 2019 novel coronavirus (2019-nCoV) by real-time RT-PCR. Euro Surveill 25.

Costanzo M, De Giglio MAR, \& Roviello GN (2020). SARS-CoV-2: Recent Reports on Antiviral Therapies Based on Lopinavir/Ritonavir, Darunavir/Umifenovir, Hydroxychloroquine, Remdesivir, Favipiravir and Other Drugs for the Treatment of the New Coronavirus. Curr Med Chem.

Cui J, Li F, \& Shi ZL (2019). Origin and evolution of pathogenic coronaviruses. Nat Rev Microbiol 17: 181-192.

Day M (2020). Covid-19: identifying and isolating asymptomatic people helped eliminate virus in Italian village. BMJ 368: m1165.

Deng L, Li C, Zeng Q, Liu X, Li X, Zhang H, et al. (2020). Arbidol combined with LPV/r versus LPV/r alone against Corona Virus Disease 2019: A retrospective cohort study. J Infect.

Dong L, Hu S, \& Gao J (2020). Discovering drugs to treat coronavirus disease 2019 (COVID-19). Drug Discov Ther 14: 58-60.

Drake NL, Creech HJ, \& et al. (1946). Synthetic antimalarials; the preparation and properties of 7-chloro4-(4-diethylamino-l-methylbutylamino)-quinoline (SN-7618). J Am Chem Soc 68: 1214-1216.

Du B, Qiu HB, Zhan X, Wang YS, Kang HYJ, Li XY, et al. (2020). [Pharmacotherapeutics for the New Coronavirus Pneumonia]. Zhonghua Jie He He Hu Xi Za Zhi 43: E012.

Du YX, \& Chen XP (2020). Favipiravir: Pharmacokinetics and Concerns About Clinical Trials for 2019nCoV Infection. Clin Pharmacol Ther.

Elfiky AA (2020a). Anti-HCV, nucleotide inhibitors, repurposing against COVID-19. Life Sci 248: 117477. 
Elfiky AA (2020b). Ribavirin, Remdesivir, Sofosbuvir, Galidesivir, and Tenofovir against SARS-CoV-2 RNA dependent RNA polymerase (RdRp): A molecular docking study. Life Sci 253: 117592.

Favaloro EJ, \& Lippi G (2020). Recommendations for Minimal Laboratory Testing Panels in Patients with COVID-19: Potential for Prognostic Monitoring. Semin Thromb Hemost 46: 379-382.

Ferner RE, \& Aronson JK (2020). Chloroquine and hydroxychloroquine in covid-19. BMJ 369: m1432.

Gray PE, \& Belessis Y (2020). The use of Traditional Chinese Medicines to treat SARS-CoV-2 may cause more harm than good. Pharmacol Res 156: 104776.

Guzik TJ, Mohiddin SA, Dimarco A, Patel V, Savvatis K, Marelli-Berg FM, et al. (2020). COVID-19 and the cardiovascular system: implications for risk assessment, diagnosis, and treatment options. Cardiovasc Res.

Henwood AF (2020). Coronavirus disinfection in histopathology. J Histotechnol: 1-3.

Hirschmann MT, Hart A, Henckel J, Sadoghi P, Seil R, \& Mouton C (2020). COVID-19 coronavirus: recommended personal protective equipment for the orthopaedic and trauma surgeon. Knee Surg Sports Traumatol Arthrosc.

Ho LTF, Chan KKH, Chung VCH, \& Leung TH (2020). Highlights of traditional Chinese medicine frontline expert advice in the China national guideline for COVID-19. Eur J Integr Med: 101116.

Hoffmann M, Kleine-Weber H, \& Pohlmann S (2020). A Multibasic Cleavage Site in the Spike Protein of SARS-CoV-2 Is Essential for Infection of Human Lung Cells. Mol Cell.

Hoffmann M, Kleine-Weber H, Schroeder S, Kruger N, Herrler T, Erichsen S, et al. (2020). SARS-CoV-2 Cell Entry Depends on ACE2 and TMPRSS2 and Is Blocked by a Clinically Proven Protease Inhibitor. Cell 181: 271-280 e278.

Hoffmann M, Schroeder S, Kleine-Weber H, Muller MA, Drosten C, \& Pohlmann S (2020). Nafamostat mesylate blocks activation of SARS-CoV-2: New treatment option for COVID-19. Antimicrob Agents Chemother.

Hsu YC, Liu YA, Lin MH, Lee HW, Chen TJ, Chou LF, et al. (2020). Visiting Policies of Hospice Wards during the COVID-19 Pandemic: An Environmental Scan in Taiwan. Int J Environ Res Public Health 17.

Hu XY, Logue M, \& Robinson N (2020). Antimicrobial resistance is a global problem - a UK perspective. Eur J Integr Med: 101136.

Huang J, Song W, Huang H, \& Sun Q (2020). Pharmacological Therapeutics Targeting RNA-Dependent RNA Polymerase, Proteinase and Spike Protein: From Mechanistic Studies to Clinical Trials for COVID-19. J Clin Med 9.

Huang P, Liu T, Huang L, Liu H, Lei M, Xu W, et al. (2020a). Use of Chest CT in Combination with Negative RT-PCR Assay for the 2019 Novel Coronavirus but High Clinical Suspicion. Radiology 295: 22-23.

Huang WH, Teng LC, Yeh TK, Chen YJ, Lo WJ, Wu MJ, et al. (2020b). 2019 novel coronavirus disease (COVID-19) in Taiwan: Reports of two cases from Wuhan, China. J Microbiol Immunol Infect.

Hulseberg CE, Feneant L, Szymanska-de Wijs KM, Kessler NP, Nelson EA, Shoemaker CJ, et al. (2019). Arbidol and Other Low-Molecular-Weight Drugs That Inhibit Lassa and Ebola Viruses. J Virol 93.

Júnior IJM, Polveiro RC, Souza GM, Bortolin DI, Sassaki FT, \& Lima ATM (2020). The global population of SARS-CoV-2 is composed of six major subtypes. doi: https://doi.org/10.1101/2020.04.14.040782. bioRxiv.

Jan H, Faisal S, Khan A, Khan S, Usman H, Liaqat R, et al.(2020). COVID-19: Review of Epidemiology and Potential Treatments Against 2019 Novel Coronavirus. Discoveries (Craiova) 8: e108. 
Jean SS, Lee PI, \& Hsueh PR (2020). Treatment options for COVID-19: The reality and challenges. J Microbiol Immunol Infect.

Jeffers SA, Tusell SM, Gillim-Ross L, Hemmila EM, Achenbach JE, Babcock GJ, et al. (2004). CD209L (LSIGN) is a receptor for severe acute respiratory syndrome coronavirus. Proc Natl Acad Sci U S A 101:1574815753.

Jones L, Walsh K, Willcox M, Morgan P, \& Nichols J (2020). The COVID-19 pandemic: Important considerations for contact lens practitioners. Cont Lens Anterior Eye.

Kadam RU, \& Wilson IA (2017). Structural basis of influenza virus fusion inhibition by the antiviral drug Arbidol. Proc Natl Acad Sci U S A 114: 206-214.

Kampf G, Todt D, Pfaender S, \& Steinmann E (2020). Persistence of coronaviruses on inanimate surfaces and their inactivation with biocidal agents. J Hosp Infect 104: 246-251.

Kaul D (2020). An overview of coronaviruses including the SARS-2 coronavirus - Molecular biology, epidemiology and clinical implications. Curr Med Res Pract.

Kupferschmidt K, \& Cohen J (2020). Race to find COVID-19 treatments accelerates. Science 367: 1412-1413.

Lagunas-Rangel FA, \& Chavez-Valencia V (2020). High IL-6/IFN-gamma ratio could be associated with severe disease in COVID-19 patients. J Med Virol.

Lai CC, Wang CY, Wang YH, Hsueh SC, Ko WC, \& Hsueh PR (2020). Global epidemiology of coronavirus disease 2019 (COVID-19): disease incidence, daily cumulative index, mortality, and their association with country healthcare resources and economic status. Int J Antimicrob Agents 55: 105946.

Lange C, Wolf J, Auw-Haedrich C, Schlecht A, Boneva S, Lapp T, et al. (2020). Expression of the COVID-19 receptor ACE2 in the human conjunctiva. J Med Virol.

Langevin C, Aleksejeva E, Passoni G, Palha N, Levraud JP, \& Boudinot P (2013). The antiviral innate immune response in fish: evolution and conservation of the IFN system. J Mol Biol 425: 4904-4920.

Lee NY, Li CW, Tsai HP, Chen PL, Syue LS, Li MC, et al. (2020). A case of COVID-19 and pneumonia returning from Macau in Taiwan: Clinical course and anti-SARS-CoV-2 IgG dynamic. J Microbiol Immunol Infect.

Lei P, Huang Z, Liu G, Wang P, Song W, Mao J, et al. (2020). Clinical and computed tomographic (CT) images characteristics in the patients with COVID-19 infection: What should radiologists need to know? J Xray Sci Technol.

Li G, \& De Clercq E (2020). Therapeutic options for the 2019 novel coronavirus (2019-nCoV). Nat Rev Drug Discov 19: 149-150.

Li Q, Guan X, Wu P, Wang X, Zhou L, Tong Y, et al. (2020a). Early Transmission Dynamics in Wuhan, China, of Novel Coronavirus-Infected Pneumonia. N Engl J Med 382: 1199-1207.

Li Z, Wang X, Cao D, Sun R, Li C, \& Li G (2020). Rapid review for the anti-coronavirus effect of remdesivir. Drug Discov Ther 14:73-76.

Li Z, Yi Y, Luo X, Xiong N, Liu Y, Li S, et al. (2020b). Development and clinical application of a rapid IgM-IgG combined antibody test for SARS-CoV-2 infection diagnosis. J Med Virol.

Lin LL, Shan JJ, Xie T, Xu JY, Shen CS, Di LQ, et al. (2016). Application of Traditional Chinese Medical Herbs in Prevention and Treatment of Respiratory Syncytial Virus. Evid Based Complement Alternat Med 2016: 6082729 .

Liu YC, Kuo RL, \& Shih SR (2020). COVID-19: the First Documented Coronavirus Pandemic in History. Biomed J. 
Liu YC, Liao CH, Chang CF, Chou CC, \& Lin YR (2020). A Locally Transmitted Case of SARS-CoV-2 Infection in Taiwan. N Engl J Med 382: 1070-1072.

Long Y, Hu T, Liu L, Chen R, Guo Q, Yang L, et al. (2020). Effectiveness of N95 respirators versus surgical masks against influenza: A systematic review and meta-analysis. J Evid Based Med.

Lu CC, Chen MY, \& Chang YL (2020). Potential therapeutic agents against COVID-19: What we know so far. J Chin Med Assoc.

Lu R, Zhao X, Li J, Niu P, Yang B, Wu H, et al. (2020). Genomic characterisation and epidemiology of 2019 novel coronavirus: implications for virus origins and receptor binding. Lancet 395: 565-574.

Luo E, Zhang D, Luo H, Liu B, Zhao K, Zhao Y, et al. (2020a). Treatment efficacy analysis of traditional Chinese medicine for novel coronavirus pneumonia (COVID-19): an empirical study from Wuhan, Hubei Province, China. Chin Med 15: 34.

Luo H, Tang QL, Shang YX, Liang SB, Yang M, Robinson N, et al.(2020b). Can Chinese Medicine Be Used for Prevention of Corona Virus Disease 2019 (COVID-19)? A Review of Historical Classics, Research Evidence and Current Prevention Programs. Chin J Integr Med 26:243-250.

Ma J, Huo XQ, Chen X, Zhu WX, Yao MC, Qiao YJ, et al. (2020). [Study on screening potential traditional Chinese medicines against 2019-nCoV based on Mpro and PLP]. Zhongguo Zhong Yao Za Zhi 45: 1219-1224.

Ma QX, Shan H, Zhang HL, Li GM, Yang RM, \& Chen JM (2020). Potential utilities of mask-wearing and instant hand hygiene for fighting SARS-CoV-2. J Med Virol.

Mantlo E, Bukreyeva N, Maruyama J, Paessler S, \& Huang C (2020). Antiviral activities of type I interferons to SARS-CoV-2 infection. Antiviral Res 179: 104811.

Martinez MA (2020). Compounds with Therapeutic Potential against Novel Respiratory 2019 Coronavirus. Antimicrob Agents Chemother 64.

McGonagle D, Sharif K, O'Regan A, \& Bridgewood C (2020). The Role of Cytokines including Interleukin6 in COVID-19 induced Pneumonia and Macrophage Activation Syndrome-Like Disease. Autoimmun Rev 19:102537.

McKee DL, Sternberg A, Stange U, Laufer S, \& Naujokat C (2020). Candidate drugs against SARS-CoV-2 and COVID-19. Pharmacol Res 157: 104859.

McKimm-Breschkin JL, Jiang S, Hui DS, Beigel JH, Govorkova EA, \& Lee N (2018). Prevention and treatment of respiratory viral infections: Presentations on antivirals, traditional therapies and host-directed interventions at the 5th ISIRV Antiviral Group conference. Antiviral Res 149: 118-142.

Mirijello A, D'Errico MM, Lamarca A, Piscitelli P, \& De Cosmo S (2020). Comment on Matricardi PM et al.: The first, holistic immunological model of COVID-19: implications for prevention, diagnosis, and public health measures. Pediatr Allergy Immunol.

Montesinos I, Gruson D, Kabamba B, Dahma H, Van den Wijngaert S, Reza S, et al. (2020). Evaluation of two automated and three rapid lateral flow immunoassays for the detection of anti-SARS-CoV-2 antibodies. J Clin Virol 128: 104413.

Morgenstern B, Michaelis M, Baer PC, Doerr HW, \& Cinatl J, Jr. (2005). Ribavirin and interferon-beta synergistically inhibit SARS-associated coronavirus replication in animal and human cell lines. Biochem Biophys Res Commun 326: 905-908.

Nelemans T, \& Kikkert M (2019). Viral Innate Immune Evasion and the Pathogenesis of Emerging RNA Virus Infections. Viruses 11.

Ni L, Zhou L, Zhou M, Zhao J, \& Wang DW (2020). Combination of western medicine and Chinese traditional patent medicine in treating a family case of COVID-19. Front Med 14: 210-214. 
Park SE (2020). Epidemiology, virology, and clinical features of severe acute respiratory syndrome coronavirus-2 (SARS-CoV-2; Coronavirus Disease-19). Clin Exp Pediatr 63: 119-124.

Pastick KA, Okafor EC, Wang F, Lofgren SM, Skipper CP, Nicol MR, et al. (2020). Review: Hydroxychloroquine and Chloroquine for Treatment of SARS-CoV-2 (COVID-19). Open Forum Infect Dis 7: ofaa130.

Phan LT, Nguyen TV, Luong QC, Nguyen TV, Nguyen HT, Le HQ, et al.(2020). Importation and Humanto-Human Transmission of a Novel Coronavirus in Vietnam. N Engl J Med 382: 872-874.

Pilkington V, Pepperrell T, \& Hill A (2020). A review of the safety of favipiravir - a potential treatment in the COVID-19 pandemic? J Virus Erad 6: 45-51.

Piszczatoski CR, \& Powell J (2020). Emergency Approval of Chloroquine and Hydroxychloroquine for Treatment of COVID-19. Ann Pharmacother: 1060028020925558.

Price CC, \& Roberts RM (1946). The synthesis of 4-hydroxyquinolines; through ethoxymethylene malonic ester. J Am Chem Soc 68:1204-1208.

Pujadas E, Ibeh N, Hernandez MM, Waluszko A, Sidorenko T, Flores V, et al. (2020). Comparison of SARSCoV-2 Detection from Nasopharyngeal Swab Samples by the Roche cobas(R) 6800 SARS-CoV-2 Test and a Laboratory-Developed Real-Time RT-PCR test. J Med Virol.

Qing GC, Zhang H, Bai Y, \& Luo Y (2020). Traditional Chinese and Western Medicines Jointly Beat COVID-19 Pandemic. Chin J Integr Med.

Rabaan AA, Al-Ahmed SH, Haque S, Sah R, Tiwari R, Malik YS, et al. (2020). SARS-CoV-2, SARS-CoV, and MERS-COV: A comparative overview. Infez Med 28: 174-184.

Rahman H, Carter I, Basile K, Donovan L, Kumar S, Tran T, et al.(2020). Interpret with caution: An evaluation of the commercial AusDiagnostics versus in-house developed assays for the detection of SARSCoV-2 virus. J Clin Virol 127: 104374.

Rahman N, Basharat Z, Yousuf M, Castaldo G, Rastrelli L, \& Khan H (2020). Virtual Screening of Natural Products against Type II Transmembrane Serine Protease (TMPRSS2), the Priming Agent of Coronavirus 2 (SARS-CoV-2). Molecules 25.

Reina J (2020). [Remdesivir, the antiviral hope against SARS-CoV-2]. Rev Esp Quimioter.

Ren JL, Zhang AH, \& Wang XJ (2020). Traditional Chinese medicine for COVID-19 treatment. Pharmacol Res 155: 104743.

Ren Y, Yao MC, Huo XQ, Gu Y, Zhu WX, Qiao YJ, et al. (2020). [Study on treatment of "cytokine storm" by anti-2019-nCoV prescriptions based on arachidonic acid metabolic pathway]. Zhongguo Zhong Yao Za Zhi 45: 1225-1231.

Rosa SGV, \& Santos WC (2020). Clinical trials on drug repositioning for COVID-19 treatment. Rev Panam Salud Publica 44: e40.

Rothan HA, \& Byrareddy SN (2020). The epidemiology and pathogenesis of coronavirus disease (COVID-19) outbreak. J Autoimmun 109:102433.

Saadat S, Rawtani D, \& Hussain CM (2020). Environmental perspective of COVID-19. Sci Total Environ 728: 138870 .

Sallard E, Lescure FX, Yazdanpanah Y, Mentre F, \& Peiffer-Smadja N (2020). Type 1 interferons as a potential treatment against COVID-19. Antiviral Res 178: 104791.

Schrank CL, Minbiole KPC, \& Wuest WM (2020). Are Quaternary Ammonium Compounds, the Workhorse Disinfectants, Effective against Severe Acute Respiratory Syndrome-Coronavirus-2? ACS Infect Dis. 
Schwartz J, King CC, \& Yen MY (2020). Protecting Health Care Workers during the COVID-19 Coronavirus Outbreak -Lessons from Taiwan's SARS response. Clin Infect Dis.

Shukla AM, Archibald LK, Shukla AW, Mehta HJ, \& Cherabuddi K (2020). Chloroquine and hydroxychloroquine in the context of COVID-19. Drugs Context 9.

Siegel D, Hui HC, Doerffler E, Clarke MO, Chun K, Zhang L, et al.(2017). Discovery and Synthesis of a Phosphoramidate Prodrug of a Pyrrolo[2,1-f][triazin-4-amino] Adenine C-Nucleoside (GS-5734) for the Treatment of Ebola and Emerging Viruses. J Med Chem 60:1648-1661.

Simsek Yavuz S, \& Unal S (2020). Antiviral treatment of COVID-19. Turk J Med Sci 50: 611-619.

Singhal T (2020). A Review of Coronavirus Disease-2019 (COVID-19). Indian J Pediatr 87: 281-286.

Stahlmann R, \& Lode H (2020). Medication for COVID-19-an Overview of Approaches Currently Under Study. Dtsch Arztebl Int 117:213-219.

Sturrock BR, \& Chevassut TJ (2020). Chloroquine and COVID-19 - a potential game changer? Clin Med (Lond).

Su YJ, \& Lai YC (2020). Comparison of clinical characteristics of coronavirus disease (COVID-19) and severe acute respiratory syndrome (SARS) as experienced in Taiwan. Travel Med Infect Dis: 101625.

Tan L, Wang Q, Zhang D, Ding J, Huang Q, Tang YQ, et al. (2020). Lymphopenia predicts disease severity of COVID-19: a descriptive and predictive study. Signal Transduct Target Ther 5: 33.

Teschke R, Larrey D, Melchart D, \& Danan G (2016). Traditional Chinese Medicine (TCM) and Herbal Hepatotoxicity: RUCAM and the Role of Novel Diagnostic Biomarkers Such as MicroRNAs. Medicines (Basel) 3 .

Thabet L, Mhalla S, Naija H, Jaoua MA, Hannachi N, Fki-Berrajah L, et al. (2020). SARS-CoV-2 infection virological diagnosis. Tunis Med 98: 304-308.

Torres AE, Lyons AB, Narla S, Kohli I, Parks-Miller A, Ozog D, et al. (2020). Ultraviolet-C and other methods of decontamination of filtering facepiece N-95 respirators during the COVID-19 pandemic. Photochem Photobiol Sci.

Tsay SF, Kao CC, Wang HH, \& Lin CC (2020). Nursing's response to COVID-19: Lessons learned from SARS in Taiwan. Int J Nurs Stud 108: 103587.

Tu YF, Chien CS, Yarmishyn AA, Lin YY, Luo YH, Lin YT, et al.(2020). A Review of SARS-CoV-2 and the Ongoing Clinical Trials. Int J Mol Sci 21.

Ul Qamar MT, Alqahtani SM, Alamri MA, \& Chen LL (2020). Structural basis of SARS-CoV-2 3CL(pro) and anti-COVID-19 drug discovery from medicinal plants. J Pharm Anal.

Vankadari N (2020). Arbidol: A potential antiviral drug for the treatment of SARS-CoV-2 by blocking trimerization of the spike glycoprotein. Int J Antimicrob Agents: 105998.

Vasarhelyi B, Kristof K, Ostorhazi E, Szabo D, Prohaszka Z, \& Merkely B (2020). The diagnostic value of rapid anti IgM and IgG detecting tests in the identification of patients with SARS CoV-2 virus infection. Orv Hetil 161: 807-812.

Verbeek JH, Rajamaki B, Ijaz S, Sauni R, Toomey E, Blackwood B, et al. (2020). Personal protective equipment for preventing highly infectious diseases due to exposure to contaminated body fluids in healthcare staff. Cochrane Database Syst Rev 4: CD011621.

Verdecchia P, Cavallini C, Spanevello A, \& Angeli F (2020). The pivotal link between ACE2 deficiency and SARS-CoV-2 infection. Eur J Intern Med. 
Vidal P (2020). Interferon alpha in cancer immunoediting: From elimination to escape. Scand J Immunol 91: e12863.

Wan S, Xiang Y, Fang W, Zheng Y, Li B, Hu Y, et al. (2020). Clinical features and treatment of COVID-19 patients in northeast Chongqing. J Med Virol.

Wang CJ, Ng CY, \& Brook RH (2020). Response to COVID-19 in Taiwan: Big Data Analytics, New Technology, and Proactive Testing. JAMA.

Wang D, Hu B, Hu C, Zhu F, Liu X, Zhang J, et al. (2020a). Clinical Characteristics of 138 Hospitalized Patients With 2019 Novel Coronavirus-Infected Pneumonia in Wuhan, China. JAMA.

Wang X, Cao R, Zhang H, Liu J, Xu M, Hu H, et al. (2020b). The anti-influenza virus drug, arbidol is an efficient inhibitor of SARS-CoV-2 in vitro. Cell Discov 6: 28.

Wang YX, Ma JR, Wang SQ, Zeng YQ, Zhou CY, Ru YH, et al. (2020c). Utilizing integrating network pharmacological approaches to investigate the potential mechanism of Ma Xing Shi Gan Decoction in treating COVID-19. Eur Rev Med Pharmacol Sci 24: 3360-3384.

Wang Z, Chen X, Lu Y, Chen F, \& Zhang W (2020). Clinical characteristics and therapeutic procedure for four cases with 2019 novel coronavirus pneumonia receiving combined Chinese and Western medicine treatment. Biosci Trends 14: 64-68.

Wong SH, Lui RN, \& Sung JJ (2020). Covid-19 and the digestive system. J Gastroenterol Hepatol 35: 744-748.

Wu A, Peng Y, Huang B, Ding X, Wang X, Niu P, et al. (2020a). Genome Composition and Divergence of the Novel Coronavirus (2019-nCoV) Originating in China. Cell Host Microbe 27: 325-328.

Wu R, Wang L, Kuo HD, Shannar A, Peter R, Chou PJ, et al.(2020b). An Update on Current Therapeutic Drugs Treating COVID-19. Curr Pharmacol Rep: 1-15.

Wu YC, Chen CS, \& Chan YJ (2020). The outbreak of COVID-19: An overview. J Chin Med Assoc 83: 217-220.

Yan C, Cui J, Huang L, Du B, Chen L, Xue G, et al. (2020). Rapid and visual detection of 2019 novel coronavirus (SARS-CoV-2) by a reverse transcription loop-mediated isothermal amplification assay. Clin Microbiol Infect.

Ye XT, Luo YL, Xia SC, Sun QF, Ding JG, Zhou Y, et al. (2020). Clinical efficacy of lopinavir/ritonavir in the treatment of Coronavirus disease 2019. Eur Rev Med Pharmacol Sci 24: 3390-3396.

Yen MY, Schwartz J, Chen SY, King CC, Yang GY, \& Hsueh PR (2020). Interrupting COVID-19 transmission by implementing enhanced traffic control bundling: Implications for global prevention and control efforts. J Microbiol Immunol Infect.

Yip CC, Ho CC, Chan JF, To KK, Chan HS, Wong SC, et al. (2020). Development of a Novel, Genome Subtraction-Derived, SARS-CoV-2-Specific COVID-19-nsp2 Real-Time RT-PCR Assay and Its Evaluation Using Clinical Specimens. Int J Mol Sci 21.

Zeng LY, Yang J, \& Liu S (2017). Investigational hemagglutinin-targeted influenza virus inhibitors. Expert Opin Investig Drugs 26:63-73.

Zhang D, Zhang B, Lv JT, Sa RN, Zhang XM, \& Lin ZJ (2020). The clinical benefits of Chinese patent medicines against COVID-19 based on current evidence. Pharmacol Res 157: 104882.

Zhang YS, Cong WH, Zhang JJ, Guo FF, \& Li HM (2020). [Research progress of intervention of Chinese herbal medicine and its active components on human coronavirus]. Zhongguo Zhong Yao Za Zhi 45: 12631271 . 
Zhao B, Liu S, Liu Y, Li G, \& Zhang Q (2020). [Liquid chromatography tandem mass spectrometry for therapeutic drug monitoring of voriconazole in heat-inactivated blood samples: its application during COVID19 pandemic]. Nan Fang Yi Ke Da Xue Xue Bao 40: 342-345.

Zhong Z, Xie X, Huang W, Zhao W, Yu Q, \& Liu J (2020). Chest CT findings and clinical features of coronavirus disease 2019 in children. Zhong Nan Da Xue Xue Bao Yi Xue Ban 45: 236-242.

Zhou F, Yu T, Du R, Fan G, Liu Y, Liu Z, et al. (2020a). Clinical course and risk factors for mortality of adult inpatients with COVID-19 in Wuhan, China: a retrospective cohort study. Lancet 395:1054-1062.

Zhou J, Li C, Liu X, Chiu MC, Zhao X, Wang D, et al. (2020b). Infection of bat and human intestinal organoids by SARS-CoV-2. Nat Med.

Zhou Q, Wei X-S, Xiang X, Wang X, Wang Z-H, Chen V, et al.(2020c). Interferon-a2b treatment for COVID19. doi: https://doi.org/10.1101/2020.04.06.20042580. medRxiv.

Zhu Z, Lu Z, Xu T, Chen C, Yang G, Zha T, et al. (2020). Arbidol monotherapy is superior to lopinavir/ritonavir in treating COVID-19. J Infect.

Ziegler CGK, Allon SJ, Nyquist SK, Mbano IM, Miao VN, Tzouanas CN, et al. (2020). SARS-CoV-2 Receptor ACE2 Is an Interferon-Stimulated Gene in Human Airway Epithelial Cells and Is Detected in Specific Cell Subsets across Tissues. Cell.

Figure legends

Figure 1. Confirmed cases in Taiwan. (A) Number of confirmed cases of coronavirus (COVID-19) in Taiwan from January to May 2020 . (B) The numbers are divided into several 10-year age groups.

Figure 2. Symptoms of SARS-CoV-2. Symptoms of SARS-CoV-2 include fever, dyspnoea, cough and loss of taste or smell.

Figure 3. The schematic structure of SARS-CoV-2. SARS-CoV-2 encodes four major structural proteins, including the envelope $(\mathrm{E})$ protein, membrane $(\mathrm{M})$ protein, nucleocapsid $(\mathrm{N})$ protein and spike $(\mathrm{S})$ protein.

Figure 4. The genome size of SARS-CoV-2. The length of the SARS-CoV-2 genome is approximately $30 \mathrm{~kb}$.

Figure 5. The life cycle of SARS-CoV-2. The SARS-CoV-2 life cycle consists of nine major stages: virus entry either via fusion (1A) or via endocytosis (1B), (2) viral RNA release, (3) translation of viral replication machinery protein, (4) proteolysis, (5) RNA replication, (6) sub-genomic transcription, (7) translation of viral structure protein, (8) virion assembly and (9) virion release.

Figure 6. Three candidate diagnostic reverse transcriptase polymerase chain reaction assays for SARS-CoV-2. The relative genome positions of virions are used to assay for SARS-CoV-2. The three target screening assays include the $\mathrm{E}$ (envelope) gene assay, RNA-dependent RNA polymerase (RdRp) gene assay and $\mathrm{N}$ (nucleocapsid) gene assay.

Figure 7. Policies for controlling mask distribution and mask wearing to prevent viral transmission in Taiwan.

Figure 8. Design of the three-layer non-medical face masks for the protection of the general public against viral infection. The three-layer material is made from pure polypropylene melt-blown polymer (middle layer), placed between two non-woven fabric layers. The outer layer is fluid repellent, while and inner layer absorbs moisture.

Figure 9. Chemical structures of hydroxychloroquine, chloroquine, remdesivir, favipiravir, ribavirin, lopinavir/ritonavir, arbidol and camostat mesylate.

Figure 10. Molecular pharmacologic mechanisms of ongoing therapeutic COVID-19 agents. 
Figure 11. Molecular mechanisms of chloroquine and hydroxychloroquine.

Figure 12. Molecular docking of remdesivir and favipiravir binding to the RNA-dependent RNA polymerase (RdRp). (A) The right portion is the structure of remdesivir, while the left portion shows its molecular docking using Discovery Studio 2020. Remdesivir is presented using a stick model. The carbon atoms of remdesivir are coloured green. (B) The right portion shows the structure of favipiravir, while the left portion is its molecular docking using Discovery Studio 2020. Favipiravir is presented using a stick model. The carbon atoms of favipiravir are coloured green.

Figure 13. Molecular docking of ritonavir and lopinavir binding to the 3-chymotrypsin-like cysteine protease (3CLpro). (A) The right portion is the structure of ritonavir, while the left portion shows its molecular docking using Discovery Studio 2020. Ritonavir is presented using a stick model. The carbon atoms of ritonavir are coloured green. (B) The right portion is the structure of lopinavir, while the left portion shows its molecular docking using Discovery Studio 2020. Lopinavir is presented using a stick model. The carbon atoms of lopinavir are coloured green.

Figure 14. Schematic overview of type I interferon-mediated immune response mechanism for SARS-CoV, MERS-CoV and SARS-CoV-2.

Figure 15. Synthesis of remdesivir.

Figure 16. Synthesis of chloroquine (CQ).

Figure 17. Traditional Chinese medicine (TCM)-based treatment for patients with distinct clinical manifestations.

Figure 1

A.

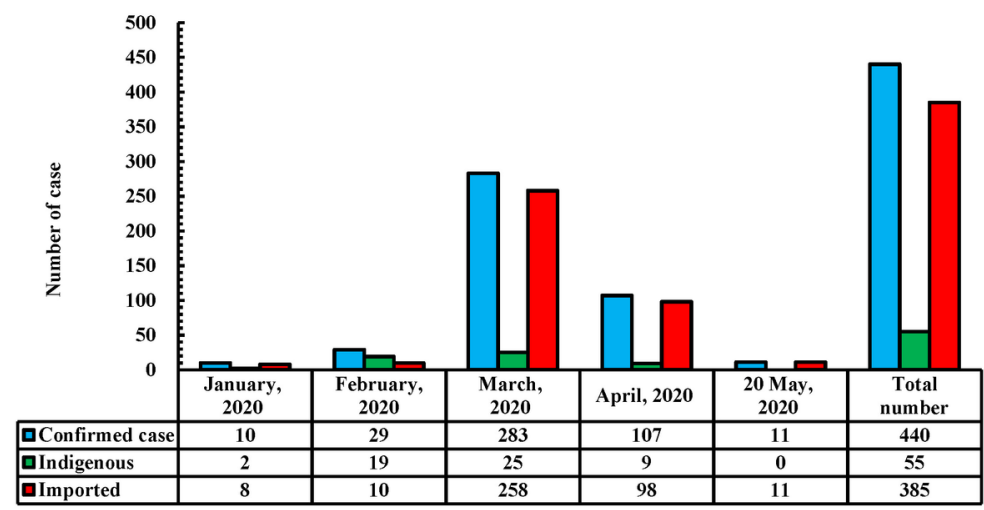

B.

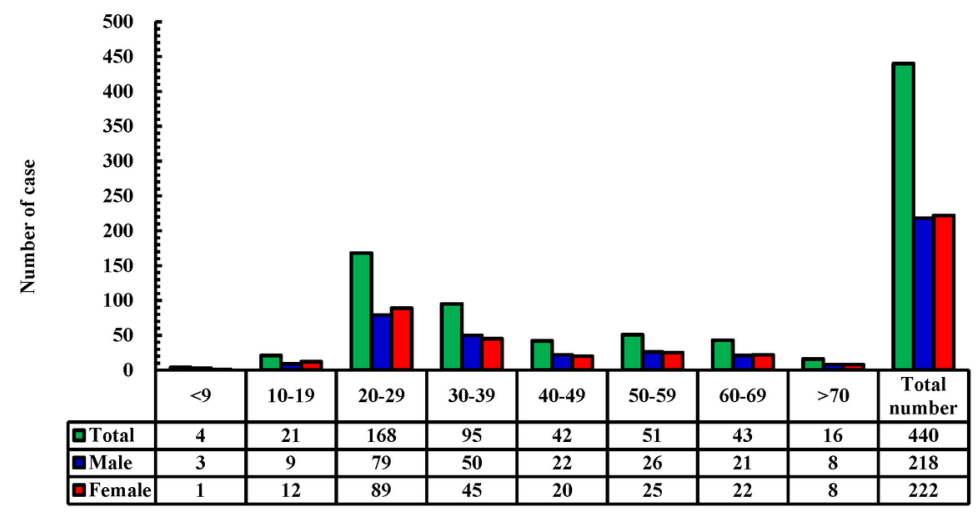


Figure 2

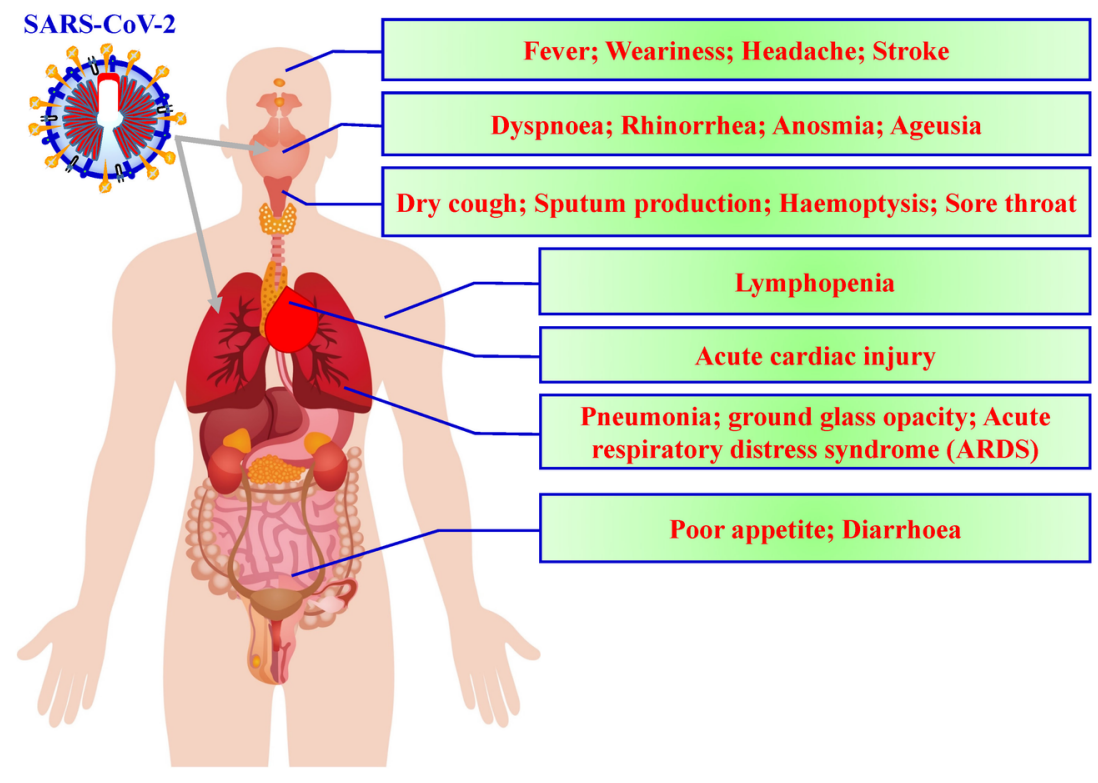

Figure 3

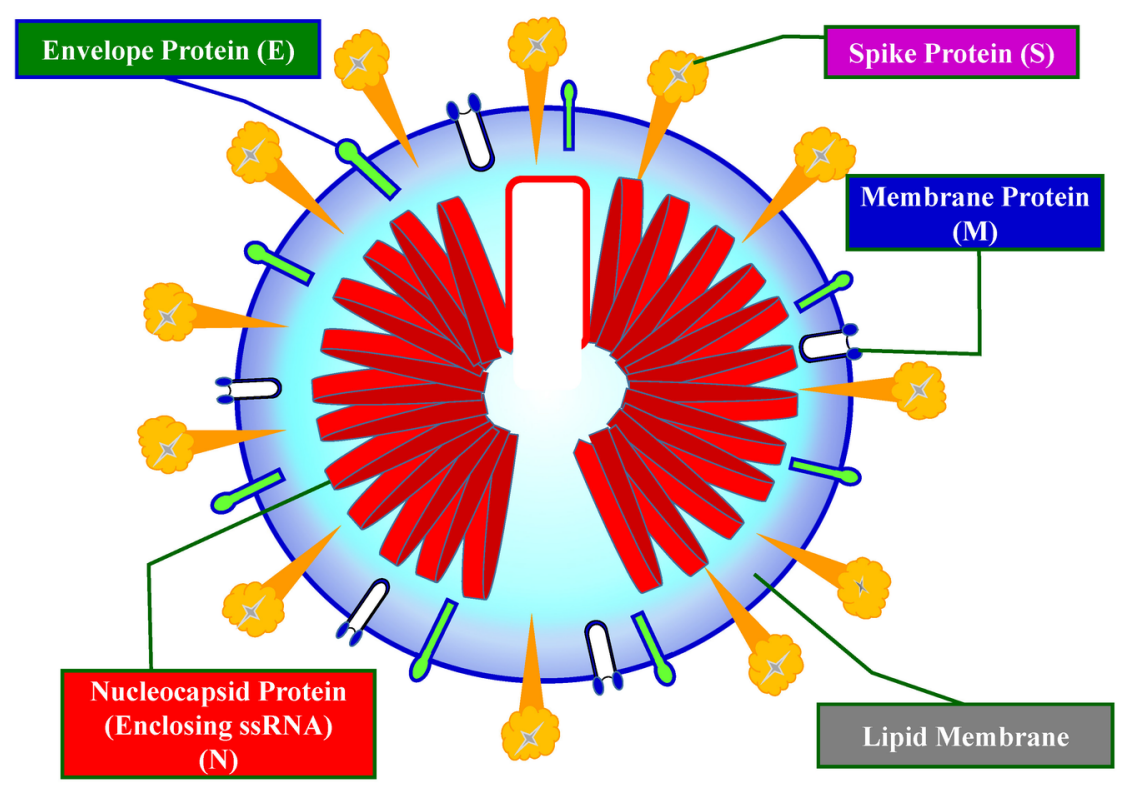


Figure 4

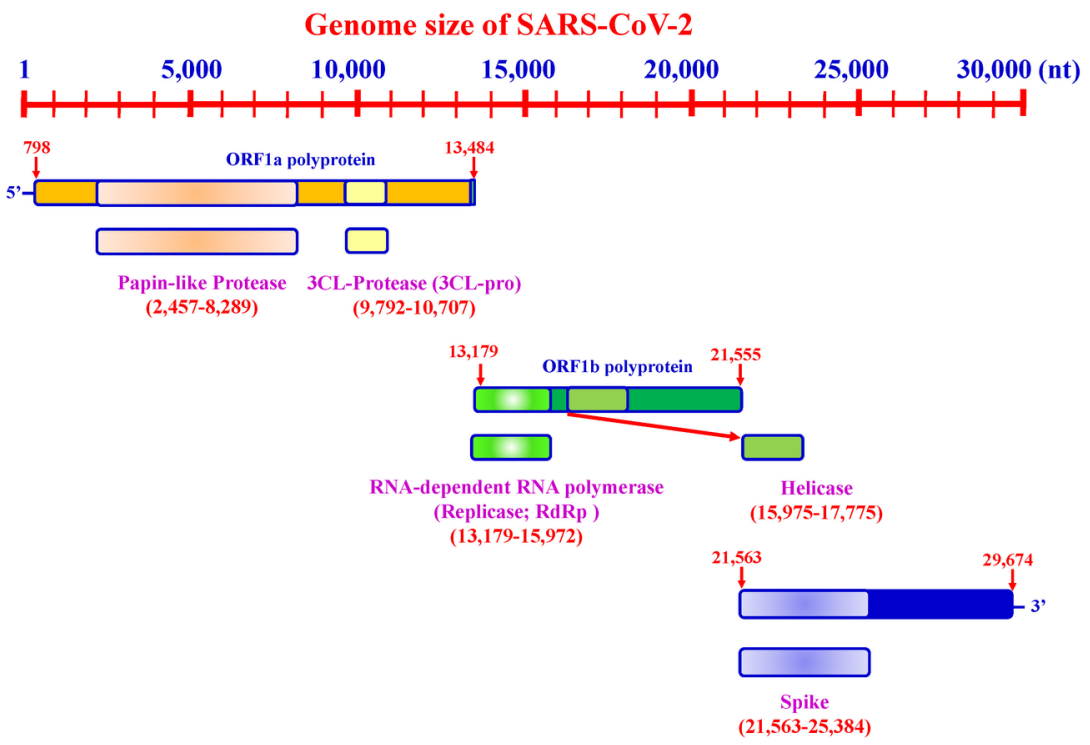

Figure 5

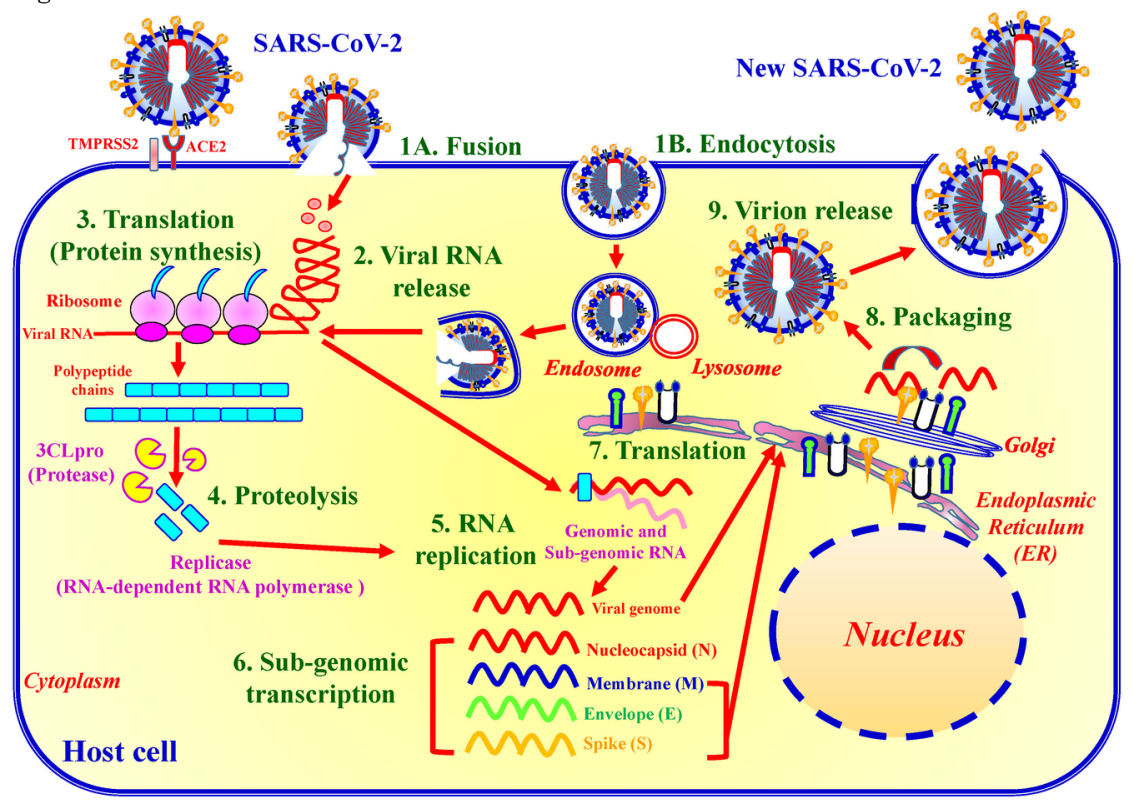


Figure 6

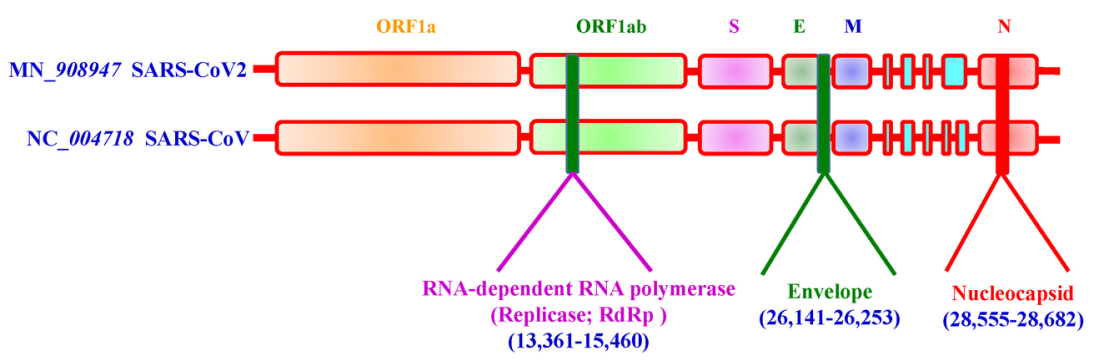

Figure 7

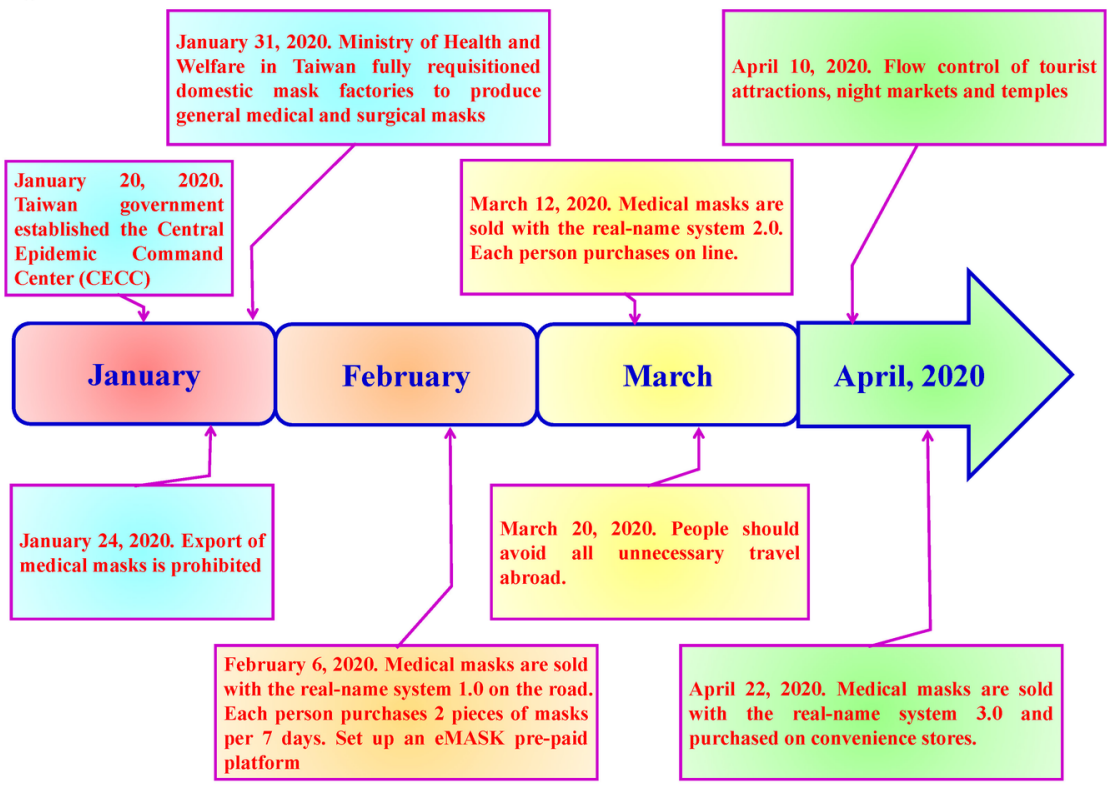


Figure 8
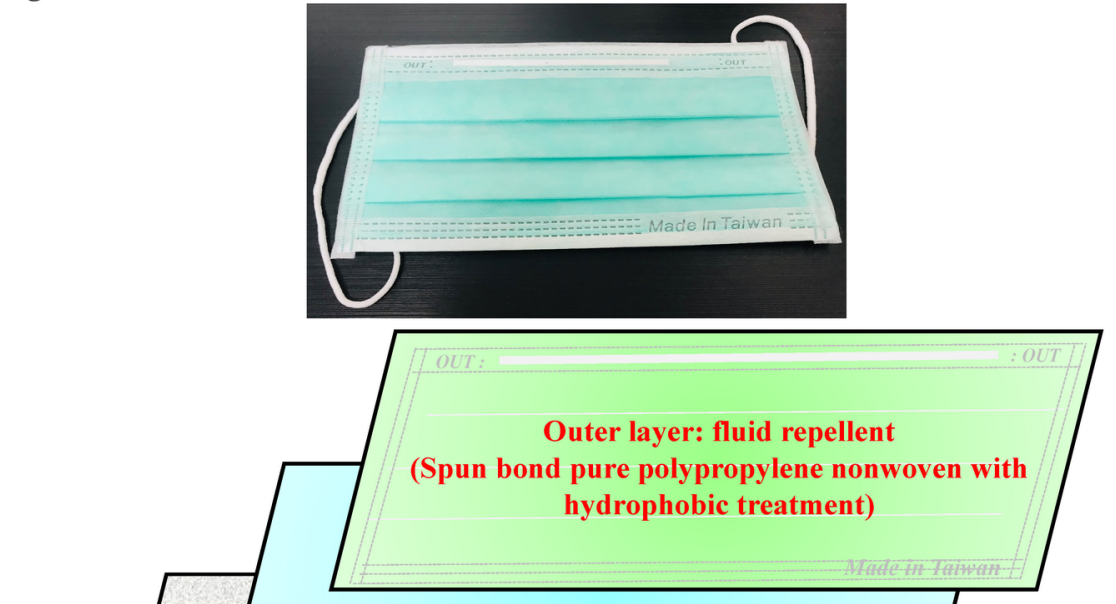

Middle layer: as filter to barrier to germ (Meltblown pure polypropylene nonwoven. Electret treatment)

Inner layer: moisture absorption

(Spun bond PP nonwoven with hydrophilic treatment)

Figure 9

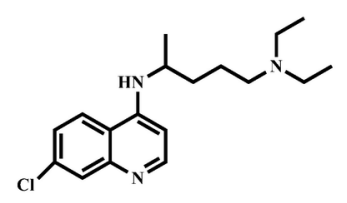

Chloroquine (Aralan

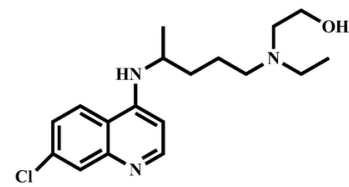

Hydroxychloroquine (Plaquenil $\left.{ }^{\mathbb{8}}\right)$

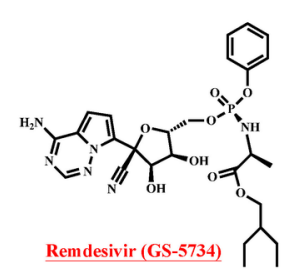

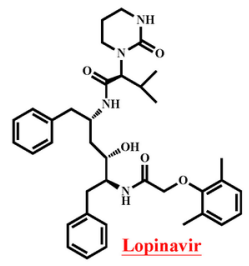<smiles>Cn1cc(F)nc(C(=O)C(C)(C)C)c1=O</smiles>

Favipiravir (Avigan $\left.{ }^{8}\right)$

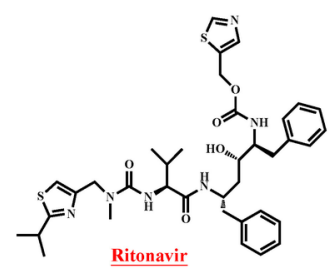

$\underline{\text { Ritonavir }}$

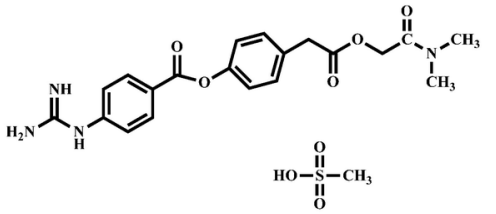

Camostat mesylate (Foipan ${ }^{\circledR}$ )<smiles>CCOC(=O)c1c(CCc2ccccc2)n(C)c2cc([123I])c([18OH])c(CN(C)C)c12</smiles>

Arbidol (Umifen ovir 


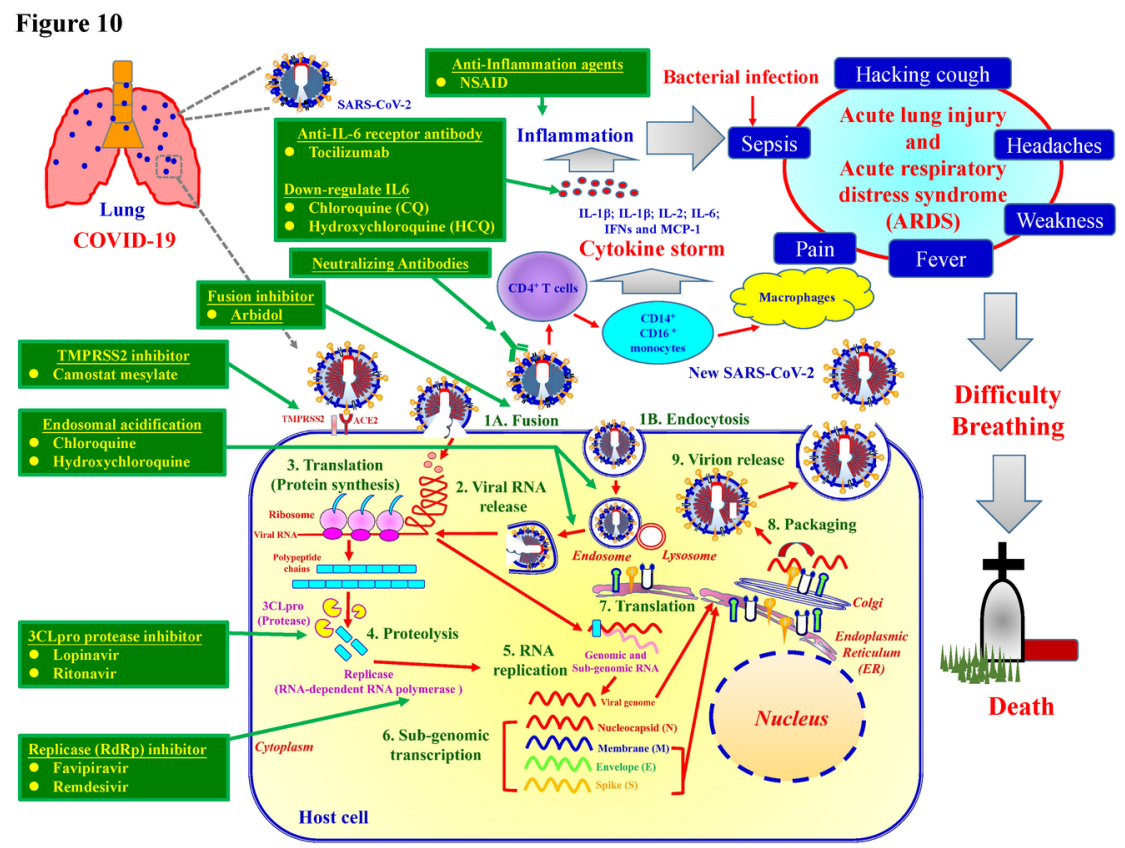

Figure 11

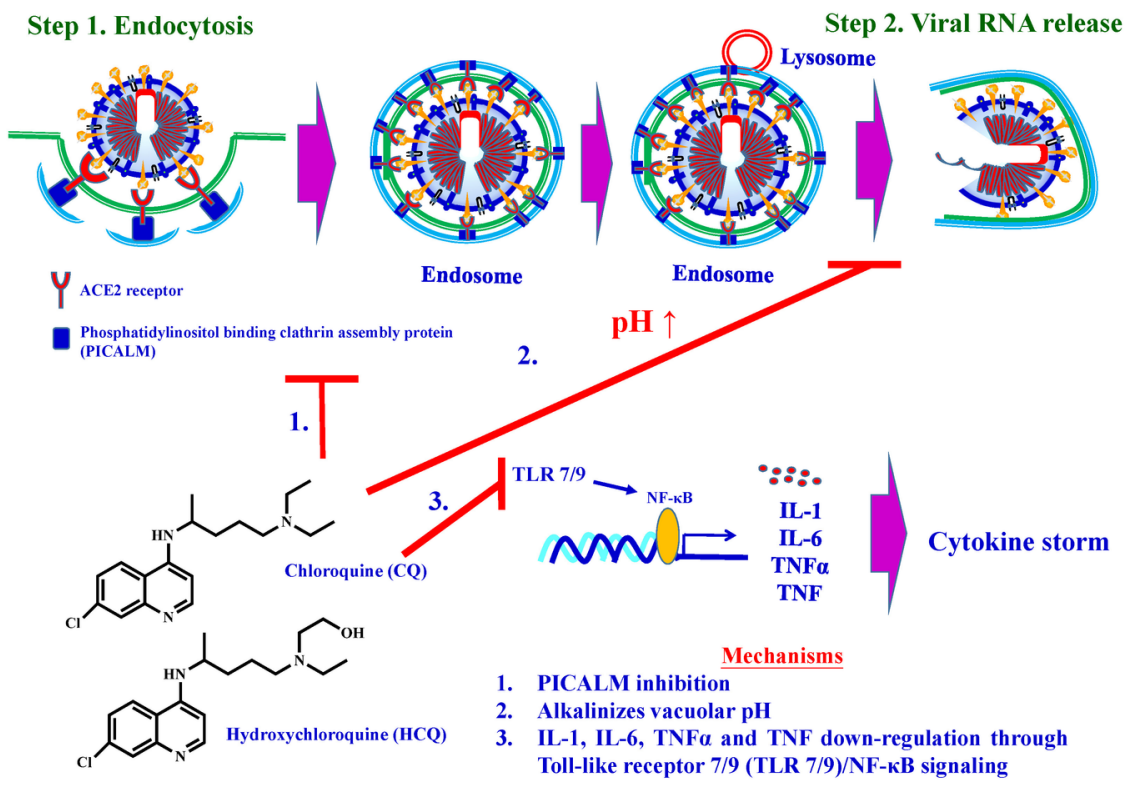


Figure 12

A.
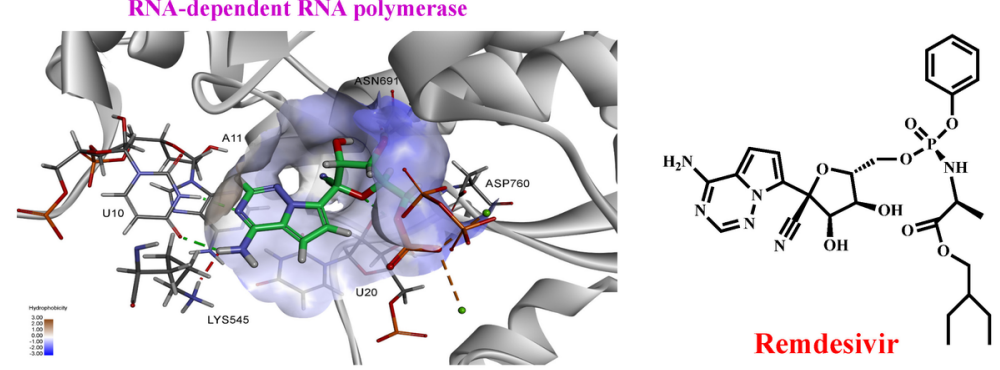

B.

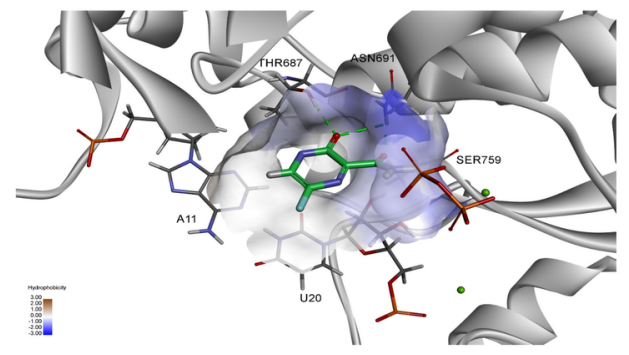

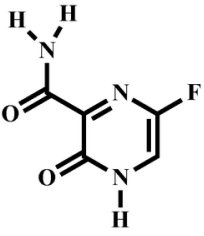

Favipiravir

Figure 13

A.

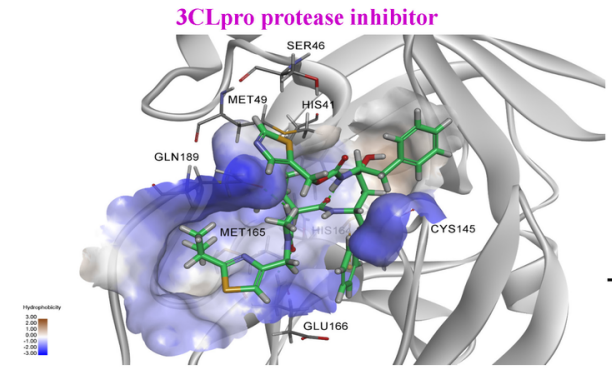

B.

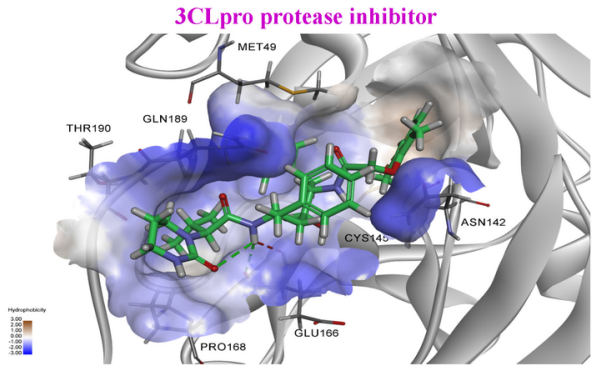

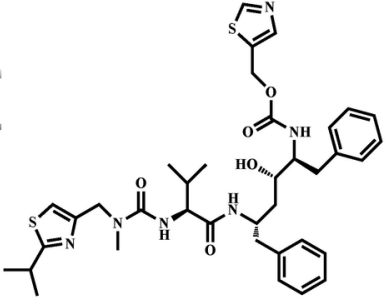

Ritonavir

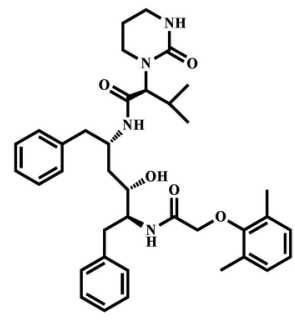

Lopinavir 
Figure 14

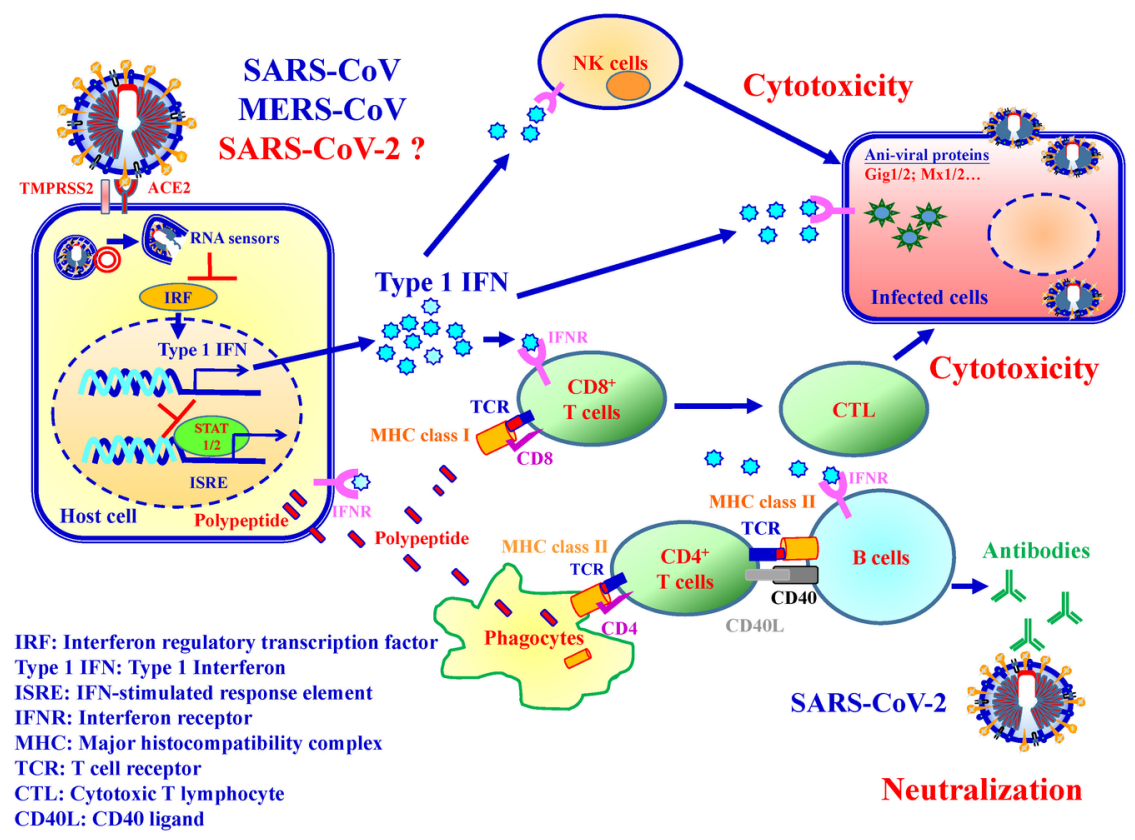

Figure 15

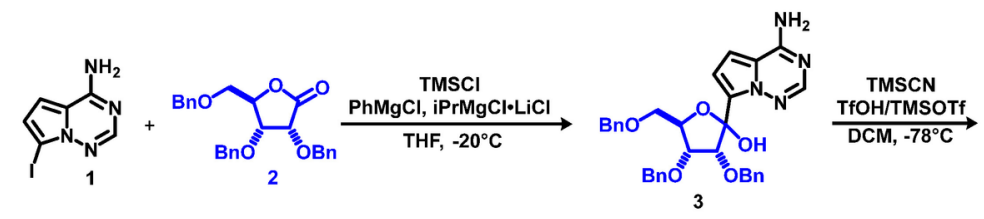

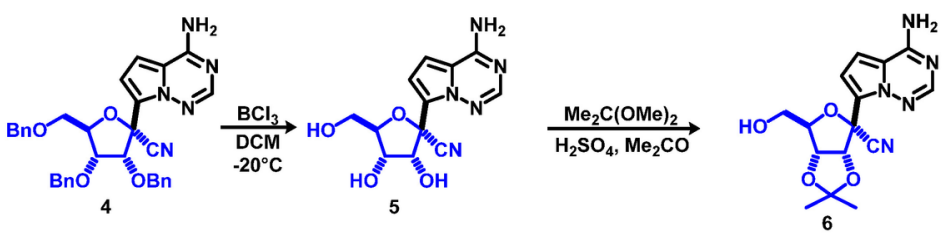

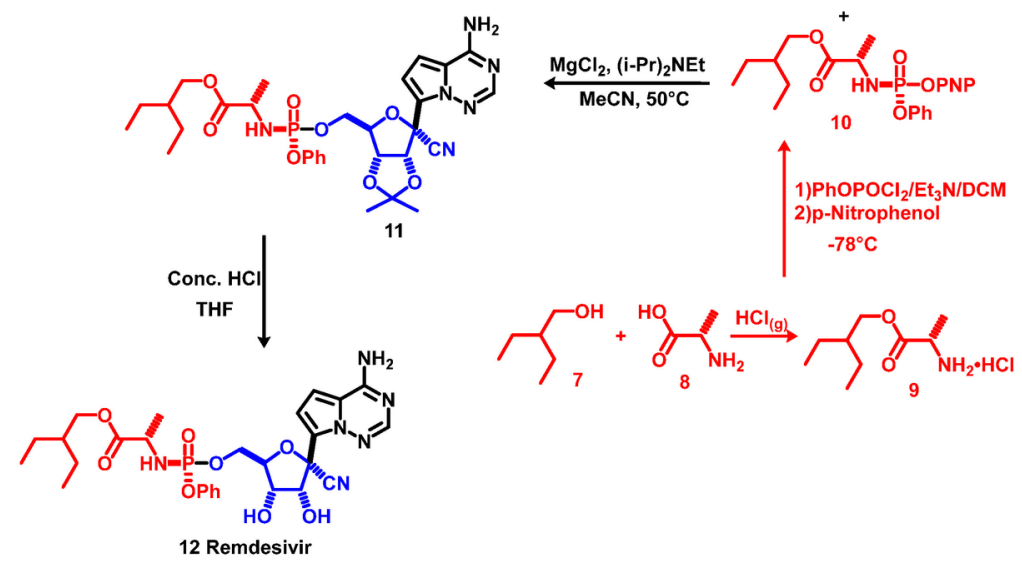


Figure 16<smiles>CCOC=C(C(=O)OCC)C(=O)OCC</smiles><smiles>O=C(O)c1cnc2cc(Cl)ccc2c1O</smiles><smiles>CCOC(=O)CC(C)=O</smiles><smiles>CCN(CC)CCCC(C)N</smiles>

24
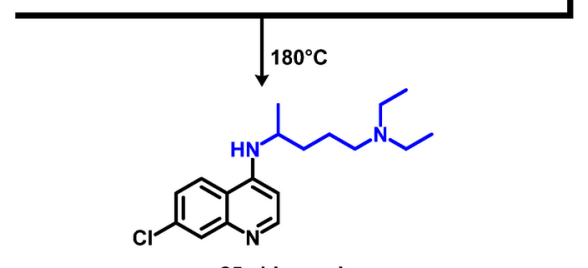

Figure 17

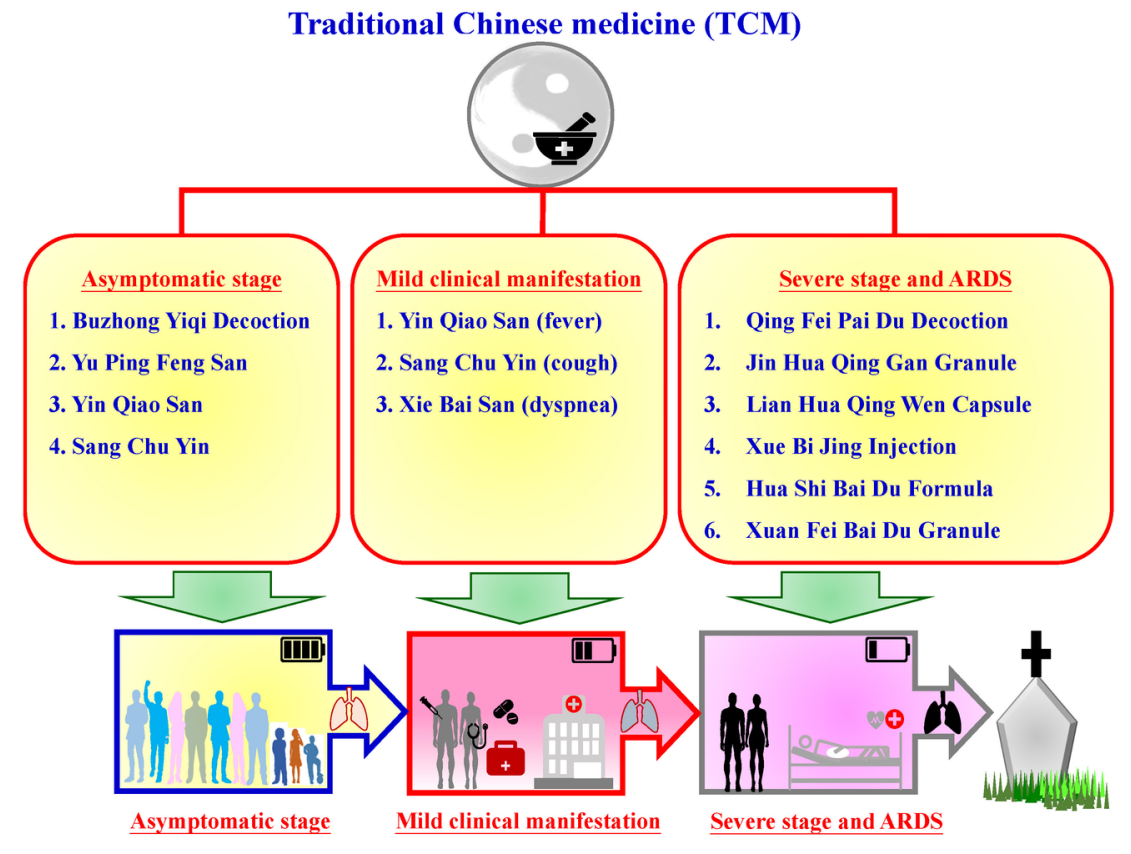

\section{Hosted file}

Table. docx available at https ://authorea.com/users/324816/articles/452902-approaches-towardsfighting-covid-19-in-taiwan 